\title{
$7 \quad$ Photochromic Reaction by Red Light via Triplet Fusion Upconversion
}

8

9 Michel Sliwa ${ }^{\ddagger}$, Jiro Abe ${ }^{* \dagger}$

ku, Sagamihara, Kanagawa 252-5258, Japan

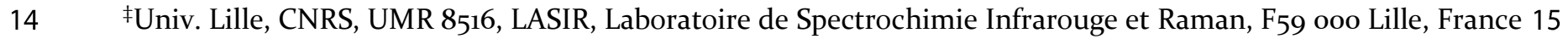

16 \$Leuven Chem\&Tech: Molecular Imaging and Photonics (MIP), KU Leuven, Celestijnenlaan 20oF, P.O. Box 2404, 17

3001 Leuven, Belgium

18 ABSTRACT: Red or near infrared (NIR) light responsive molecules have received much attention for biological and material 19 applications because potentially harmful UV light for materials and cells is not required for the photochemical reactions. 20 Although some molecular designs for photochromic molecules to increase the photosensitivity to red or NIR light have 21 been reported, the strategies are limited to the extension of $\pi$-conjugation length and the utilization of charge transfer 22 transition or energy and electron transfers. Triplet fusion is an attractive tool to cause chemical reactions by converting low 23 energy excitation light to high energy upconversion light. However, the efficient use of the high energy of upconversion 24 light is difficult because almost all reported triplet fusion systems rely on re-absorption of upconversion light. Here, we 25 demonstrated the red-light driven photochromism via the triplet fusion of a phenoxyl-imidazolyl radical complex, Pery26 RPIC, that has a covalently bonded perylene as an annihilator unit. The femtosecond time-resolved absorption and 27 fluorescence spectroscopy revealed that this photochromic reaction proceeds by the highly efficient singlet energy transfer from the annihilator unit to the photochromic unit. This strategy can be applied not only to the development of visible and NIR light responsive photochromic system but also to various photochemical reactions.

\section{INTRODUCTION}

Photochromic molecules that respond to red or near-

infrared (NIR) light have advantages such as high 36 penetration inside of biological tissues or various media

37 and no requirement of harmful UV light irradiation to 38 materials and cells, leading to application in biological and 39 material chemistry. ${ }^{1}$ Various visible or NIR light responsive

photochromic molecules, including negative

photochromic ones, have been investigated based on

azobenzene, ${ }^{2-4} \quad$ spiropyran, ${ }^{5-7}$ diarylethene, ${ }^{8-11}$ donor43 acceptor Stenhouse adduct (DASA), ${ }^{12-16}$ imidazole dimer, 44 phenoxyl-imidazolyl radical complex (PIC), ${ }^{17-24}$ and so 45 on. ${ }^{25-31}$ The typical approaches to extend the absorption $46 \quad$ band to the longer-wavelength region is the extension of $47 \pi$-conjugation length or the introduction of electron donor

48 and withdrawing substituents to reduce the HOMO- 49 LUMO energy gap. However, these approaches sometimes 50 require the time-consuming synthetic procedures and 51 strongly affect the efficiency of the photochromic reaction 52 or the stability of the photochromic isomers.

53 Triplet fusion upconversion, also termed triplet-triplet 54 annihilation upconversion, is one of the photophysical 
Page 1 of 24 Journal of the American Chemical Society

55 processes that converts lower-energy photons into higher Figure 1. (a) Reaction mechanism of the photochromism 56 energy photons. ${ }^{32,33}$ This methodology has been attracted utilizing the excited singlet state generated by triplet fusion. 57 attention for the application to material and biological (b) Molecular structures of $\mathrm{PdPh}_{4} \mathrm{TBP}$ and Pery-RPIC. 58 sciences because of the high efficiency even under weak

59 light such as sun light and incoherent continuous light,34-60

${ }^{44}$ compared with the other upconversion methods based the PIC derivatives and shows a sequential photochromism on two-photon absorption and multistep excitation of accompanied with the biradicalquinoidal valence lanthanides. ${ }^{45-47}$ The triplet fusion system consists of two isomerization following the photo-induced bond breaking chemical species, a triplet sensitizer and an annihilator. to form the transient colored isomers as shown in Scheme The annihilator receives the energy from the excited triplet $1 .{ }^{65}$ The biradical and the quinoidal forms are collectively $\left(T_{1}\right)$ state of the sensitizer via triplet-triplet energy transfer called the open-ring form. Perylene has been known as an (TTET) and excited to the $T_{1}$ state. Collision between the efficient annihilator for triplet fusion. ${ }^{65-67}$ We expect the two $\mathrm{T}_{1}$ annihilators generates an excited singlet $\left(\mathrm{S}_{1}\right)$ state introduction of perylene to the 2-position of the imidazole 8 and a ground $\left(\mathrm{S}_{\mathrm{o}}\right)$ state of the annihilator, leading to the ring of RPIC results in the efficient energy transfer from the 9 upconversion fluorescence from the $S_{1}$ state of the $S_{1}$ state of the perylene unit to the RPIC unit because the

10 annihilator. ${ }^{8}$ aryl group at the 2-position and the imidazole ring can

11 Triplet fusion is a powerful tool to realize indirect effectively interact with each other. The DFT calculations 12 photoexcitation leading to chemical reactions with low of Pery-RPIC, perylene and RPIC revealed that the energy

13 energy photons. Furthermore, we can control the chemical levels of the $T_{1}$ and the $S_{1}$ states of the perylene unit remain 14 reaction with high spatial and temporal resolutions unchanged by the substitution to the RPIC unit (Table $5_{5-15}$ because the triplet fusion is a two-photon absorption $S_{7}$ ). In addition, the energy level of the $S_{1}$ state of perylene 16 process. Recently, some fascinating photochemical is higher than that of RPIC, leading to the energy transfer 17 reactions by using triplet fusion and upconversion systems to induce the photochromic reaction. 18 have been reported. ${ }^{49-54}$ However, almost all approaches RESULTS AND DISCUSSION

19 are limited to the intermolecular energy exchange between

$3 \varepsilon$ highlighted in red. The

39 covalently bonded to perylene ${ }^{62,63}$ working as an annihilator (Pery-RPIC) (Figure $\mathrm{ib}$ ). PIC is a thermally type (T-type) photochromic molecule hydrogen atoms are omitted. (b) UV-vis absorption spectra 40 of Pery-RPIC $\left(2.7 \times 10^{-5} \mathrm{M}\right)$, RPIC $\left(3.8 \times 10^{-5} \mathrm{M}\right)$ and perylene 41 reversible to the photochromic unit (Figure 1a). 35

In this study, we designed a photochromic system Figure 2. (a) ORTEP representation of the molecular (a)

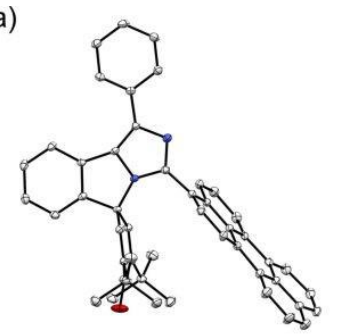

(b)

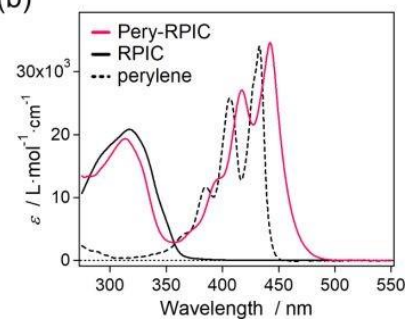

upconversion covalently bonded of a annihilator. photochromic In this molecule strategy, with the a

42 generating a colored biradical upon light irradiation and 43 thermally reverts to the initial closed form. ${ }^{64}$ RPIC is one of 44 
7

Figure 3 Transient 450-nm of Peryat $950 \mathrm{~nm}$
Scheme 1. Molecular Structures and Photochromic Reactions of RPIC and Pery-RPIC Including the Valence Isomerization Reactions

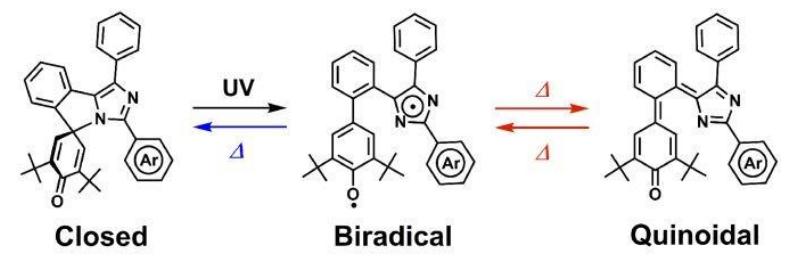

RPIC: Ar $=$ Phenyl
Pery-RPIC: Ar = Perylenyl (a)

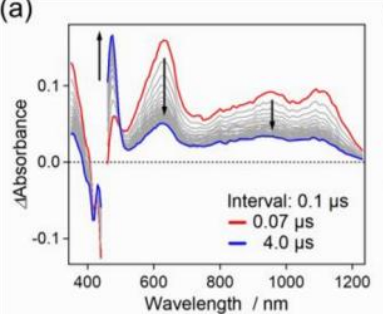

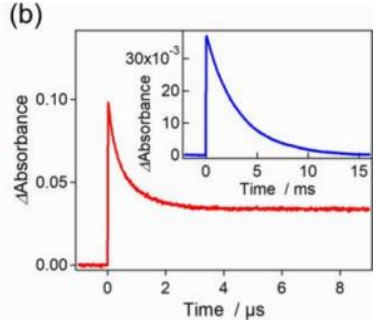

(a) absorption spectra for different time delay after the excitation with nanosecond laser pulse (energy $=0.5 \mathrm{~mJ} / \mathrm{mm}^{2}$, pulse width $=5 \mathrm{~ns}$ ) RPIC $\left(2.5 \times 10^{-5} \mathrm{M}\right)$ in acetonitrile at $298 \mathrm{~K}$ and (b) the kinetic trace in microsecond time region, inset: that in millisecond time region . 
shows the steady-state absorption spectra of Pery-RPIC, RPIC and perylene in acetonitrile. The two absorption bands in visible light region and UV light region can be attributable to the absorption of the perylene unit and the RPIC unit, respectively. The red shift of the absorption band of Pery-RPIC compared with that of perylene in visible light region indicates that the perylene unit and the RPIC unit are arranged orthogonal with each other as

8 shown in Figure $2 a$ and these two units electronically 9 interact by a spiroconjugation-like effect. ${ }^{68,69}$

\section{Photochromic Reaction in Microsecond Time}

11 Region. The photochromic reaction of Pery-RPIC via the 12 excited singlet state of the perylene unit was investigated 13 by the transient absorption technique using nanosecond 14 laser excitation. Figure za shows the transient absorption

15 spectra of Pery-RPIC in acetonitrile after 450-nm 16 nanosecond laser pulse that excites the perylene unit. The transient absorption spectrum at $0.07 \mu$ s after laser excitation shows a negative signal at $420 \mathrm{~nm}$, corresponding to the depopulation (bleaching) of the 20 initial closed form. The positive absorption bands in the visible light region are assigned to the formation of the

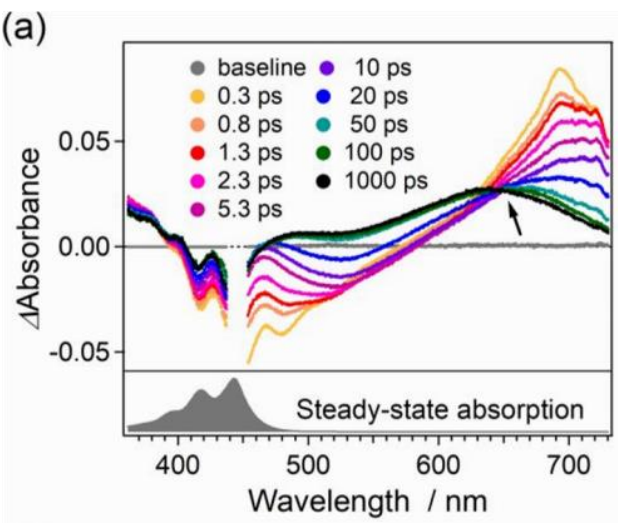

(b)

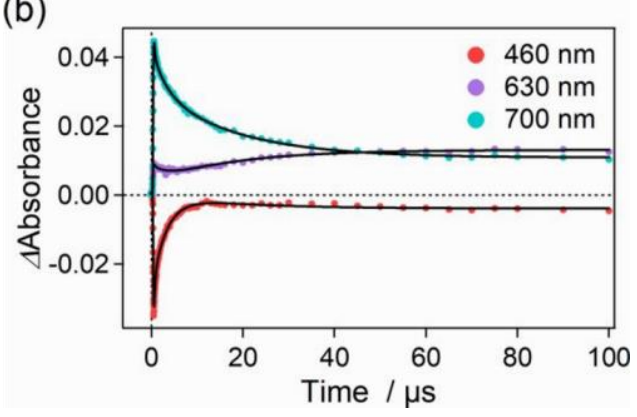
open-ring biradical form (BR) because of the similar characteristic absorption bands in visible-NIR light region 24 with those of the previously reported RPIC. ${ }^{65-67}$ From 0.0725 to $4.0 \mu$ s, a new positive absorption band at $475 \mathrm{~nm}$ is growing concomitantly with the decay of positive

Figure 4. (a) Transient absorption spectra of Pery-RPIC in

absorption bands $>500 \mathrm{~nm}$ with an isosbestic point at 499 acetonitrile, after the excitation with a femtosecond $450-\mathrm{nm}$ laser pulse (energy $=2.2 \mu \mathrm{J}$, FWHM $=140 \mathrm{fs}$ ) and the steady-

$\mathrm{nm}$ and without any changes of the depopulation band. state absorption spectrum of Pery-RPIC is shown as a filled This thermal spectral change is attributable to the valence grey spectrum. Black arrow points the isosbestic point at isomerization from BR to the quinoidal form (Q). These $648 \mathrm{~nm}$ during 5.3-10oo ps, indicating the biradical was

two around open-ring at 4.0 forms $\mu \mathrm{s}$, and reached the open-ring the thermal forms equilibrium thermally quantitatively generated from the precursor state. (b)

returned to the initial closed form while keeping the Kinetic traces of the transient absorbance of Pery-RPIC 33 thermal equilibrium within $20 \mathrm{~ms}$ (Figure $3 \mathrm{~b}$ ). after the excitation, monitored at and $700 \mathrm{~nm}$.

35 Ultrafast Excited-State Dynamics. To investigate the 36 photodissociation dynamics of Pery-RPIC sensitized by the perylene unit, we carried out femtosecond transient

absorption absorption spectra until 1 ns of experiments. Figure PeryRPIC4a shows in acetonitrile, the transient

excited with $450-\mathrm{nm}$ femtosecond laser. Just after the 40 excitation, the spectrum at $0.3 \mathrm{ps}$ is characteristic of the 41 depopulation band

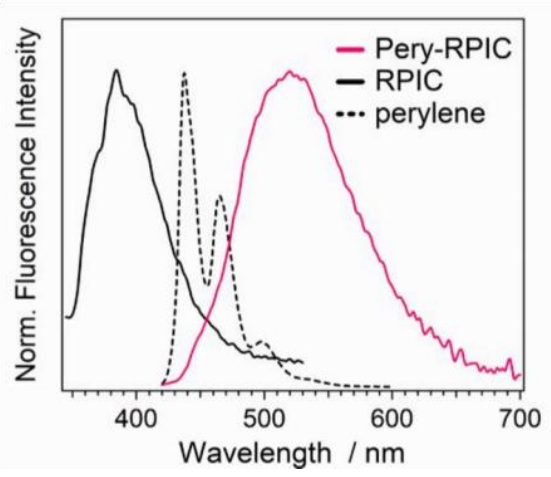
460,630 
with the bleaching signal of the $S_{o}$ state 42 and the absorption of the $S_{1}$ state of the perylene unit with 43 the $\mathrm{S}_{\mathrm{n}} \leftarrow \mathrm{S}_{1}$ absorption band at $690 \mathrm{~nm}$ accompanied with 44 the $\mathrm{S}_{0} \leftarrow \mathrm{S}_{1}$ structured stimulated emission (maxima at 48045 and $510 \mathrm{~nm}$ ). The assignment of the absorption band at $69046 \mathrm{~nm}$ and stimulated emission band to the perylene unit is in

47 agreement with the results of the literatures, the Figure 5. Fluorescence spectra of Pery-RPIC $\left(\lambda_{\text {ex. }}=410 \mathrm{~nm}\right), 48$ fluorescence steady state spectrum of perylene (Figure 5) RPIC $\left(\lambda_{\text {ex. }}=300 \mathrm{~nm}\right)$ and perylene $\left(\lambda_{\text {ex. }}=410 \mathrm{~nm}\right)$ in 49 and the transient absorption spectra for perylene alone acetonitrile at $298 \mathrm{~K}$.

50 (Figure S6).70,71 The first picosecond spectrum slightly the structured stimulated emission signals disappeared decreases without any changes of the shape or maxima in together with the appearance of a broad stimulated the time region from 0.3 to 1.3 ps. This process is assigned emission band with a maximum at $520 \mathrm{~nm}$. This broad to the vibrational relaxation of the hot Frank-Condon state stimulated emission band is similar to the steadythe localized cold excited state of the perylene unit. fluorescence spectrum of Pery-RPIC (Figure 5). Because After this relaxation, the absorption band at $690 \mathrm{~nm}$ the structured vibrational emission bands observed decreases in a few picoseconds and remains at $5.3 \mathrm{ps}$ with in stimulated emission at $520 \mathrm{~nm}$ and that the a broad positive band at $700 \mathrm{~nm}$. At the same time, fluorescence spectrum of Pery-RPIC large red-

shift compared with that of perylene, the fluorescent state formed in a few picoseconds is assigned to a partial-chargetransfer excited state (Figure 6). This is in agreement with the slower formation and reduced lifetime for this CT excited state in toluene, compared with those in acetonitrile (Figure S8 and Table S2). This CT excited state decreased in about several tens of picoseconds (Figure 4a) and the spectrum at $100 \mathrm{ps}$ is similar to the characteristic 8 band of the biradical form in the ground state (Figure $\mathrm{S}_{7}$ ).

9 The kinetic traces at different wavelengths and the 10 respective fits shown

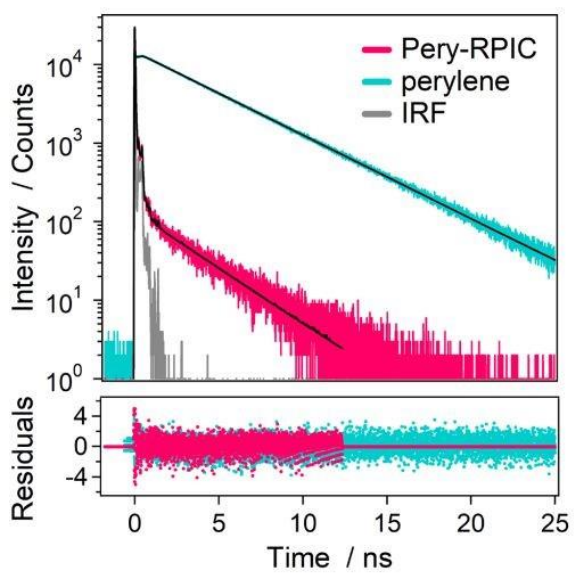
state to are not the centred shows a in Figure $4 \mathrm{~b}$ are reproduced by a sum 11 of three exponential functions and a constant. The estimated time constants are assigned to the relaxation from the FC state to the localized excited state on the 14 perylene unit $(0.26 \pm 0.008 \mathrm{ps})$, the formation of the CT excited state $(3.1 \pm 0.03 \mathrm{ps})$ and the relaxation of the $\mathrm{CT}$

excited state and the formation of the biradical (18 $\pm 0.1 \mathrm{ps})$. Figure 7. Fluorescence decays at $495 \mathrm{~nm}$ of Pery-RPIC and 17 The corresponding decay-associated spectra (DAS) are perylene in acetonitrile $\left(\lambda_{\text {ex. }}=450 \mathrm{~nm}, \mathrm{FWHM}=40\right.$ ps). 18 given in Figure S8.

19 To elucidate whether the 18 ps lifetime component is 20 assigned to the excited or the ground state, the dynamics

21 of the excited state was also investigated by the Table 1. Fluorescence Decay Time Constants and 22 femtosecond fluorescence spectroscopy with upconversion Fluorescence Quantum Yields Pery-RPIC in

23 technique. The kinetic trace of the fluorescence at $520 \mathrm{~nm} 24$ is shown in Figure S9. The fluorescence was adjusted by a 25 rise with a time constant of $3.1 \mathrm{ps}$ and a decay with a time

26 constant of 15 ps. This result indicates that the decay 27 component of $18 \mathrm{ps}$ is a CT excited emissive state. It is

28 considered from the femtosecond time-resolved 29 absorption measurement that this decay component of 18

30 ps includes not only the radiative relaxation process but 
of PIC derivatives generally proceeds from the Salso the formation of BR. Because the $\mathrm{C}-\mathrm{N}$ bond cleavage ${ }_{1}$ state with ultrafast transient absorption spectroscopy for

anti-bonding character about the $\mathrm{C}-\mathrm{N}$ bond, the $\mathrm{CT}$ photochromic imidazole dimers, the $\mathrm{C}-\mathrm{N}$ bond breaking excited state of Pery-RPIC should relax to the bond proceeds via the excited bond-dissociative state within a 34 dissociative state followed by the formation of BR. few hundreds of femtosecond.72-74 Therefore, the lifetime 35 However, no signal related to the bond dissociation of the bond-dissociative state of Pery-RPIC is too short to 36 dynamics was observed. In the time region from 5.3 ps to 1 observe in this experiment, resulting in the isosbestic point

$37 \mathrm{~ns}$, the observation of the isosbestic point at $648 \mathrm{~nm}$ with between the absorption spectra of the CT excited state and 38 low recovery of the depopulation band indicates that the BR. The plausible photochromic reaction pathway of Pery39 efficiency of the C$\mathrm{N}$ bond breaking reaction to form the RPIC is shown in Figure 6.

\section{0}

41

42

44

45

and

shown in

49 0.016,

50 single

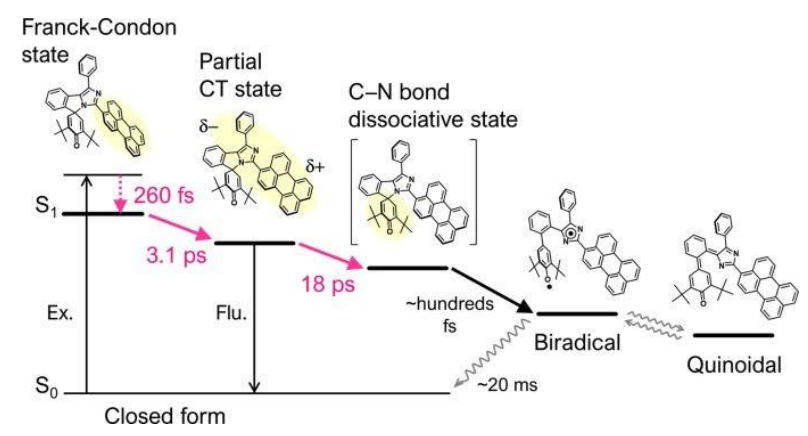

Figure 6. Plausible photochromic reaction pathway of Pery-RPIC upon excitation with visible light. Time constants of $260 \mathrm{fs}, 3.1 \mathrm{ps}$ and $18 \mathrm{ps}$ correspond to the internal conversion to the localized exited state of the perylene unit. biradical is quantitative. In the previous study of the Fluorescence Lifetime and Quantum Yield

Measurements. To evaluate the efficiency of the relaxation process from the $\mathrm{CT}$ state to the excited $\mathrm{C}-\mathrm{N} 43$ bond dissociative state of the RPIC units, the picosecond fluorescence lifetime measurements of Pery-RPIC and perylene were carried out. Fluorescence decays of Pery46 RPIC perylene excited with $450-\mathrm{nm}$ picosecond laser 47 pulse are Figure 7. The decay curve of Pery-RPIC 48 includes three decay components with the lifetimes of

0.059 and 3.0 ns while that of perylene includes a

component of the lifetime of $4.1 \mathrm{~ns}$ (Table 1 ). The main time constant $\left(\tau_{1}=0.016 \mathrm{~ns}, 91 \%\right)$ corresponds to that of the transient CT state observed by the femtosecond time-resolved spectroscopy ( $\tau=18 \mathrm{ps})$. In addition, the fluorescence quantum yield of Pery-RPIC was estimated to be o.o1 (Quantaurus-QY, Hamamatsu Photonics K. K.). According to the results of the femtosecond transient absorption experiments, the low quantum yield can be due to the efficient relaxation to the bond-dissociative state of within a few microseconds. The lifetime of the $\mathrm{T}_{1}$ state of the RPIC unit. Therefore, the relaxation of the fluorescent $\mathrm{PdPh}_{4} \mathrm{TBP}$ in the mixture is much shorter than that of state to the bonddissociative state is highly efficient. individual $\mathrm{PdPh}_{4} \mathrm{TBP}$ (Figure S11). The absorption

Red-light Induced Photochromic Reaction via spectrum at $3.05 \mu$ s can be considered to the generation of Triplet Fusion Upconversion. The ultrafast spectroscopy the $T_{1}$ state of the perylene unit of Pery-RPIC because of revealed that the photochromic reaction of Pery-RPIC is the similarity to the spectrum of the $T_{1}$ state with a efficiently sensitized by the $\mathrm{S}_{1}$ state of the perylene unit. maximum at $490 \mathrm{~nm} .{ }^{7}$ Moreover, this spectral change

While the direct excitation of the perylene unit to the $S_{1}$ from 0.15 to $3.05 \mu$ s shows isosbestic points at 575 and 6608 state requires $450-\mathrm{nm}$ light, the excitation energy to the $\mathrm{T}_{1} \mathrm{~nm}$. From these results, it can be considered that the TTET

9 state of the perylene unit is almost half of the energy to the from $\mathrm{PdPh}_{4} \mathrm{TBP}$ to Pery-RPIC quantitatively occurs in this $10 \mathrm{~S}_{1}$ state (Table $S_{5}$ ). Therefore, the generation of the $S_{1}$ state condition. At the time scale of $7^{-175 \mu s}$ (Figure $9 \mathrm{~b}$ ), the 11 via the triplet fusion can be expected. As mentioned in spectrum of the $\mathrm{T}_{1}$ state of Pery-RPIC thermally decreases 12 Introduction, $\mathrm{PdPh}_{4} \mathrm{TBP}$ has been known as an effective and then the other signal, which has a sharp absorption

triplet sensitizer. Therefore, we demonstrated the red-light band at $490 \mathrm{~nm}$ and a broad one in visible to NIR light induced photochromic reaction via triplet fusion region, remains (red line in Figure $9 \mathrm{~b}$ ). This remained upconversion of Pery-RPIC. Figure 8 shows the steady absorption spectrum corresponds to the spectrum of the 
state absorption spectra of Pery-RPIC and $\mathrm{PdPh}_{4}$ TBP in open-ring form of Pery-RPIC at the equilibrium state toluene. $\mathrm{PdPh}_{4} \mathrm{TBP}$ has the absorption peaks at $443 \mathrm{~nm}$ and shown in Figure 3, indicating the photodissociation $627 \mathrm{~nm}$. Figure 9 shows the temporal change of the reaction of Pery-RPIC is induced by the 635-nm light transient absorption spectra of the mixture of Pery-RPIC excitation (Figure 9c). The transient absorption spectrum and $\mathrm{PdPh}_{4} \mathrm{TBP}$ after the 635-nm nanosecond laser of the open-ring form was not observed when the $\mathrm{T}_{1}$ state 21 excitation. The absorption spectrum assigned to the $\mathrm{T}_{1}$ of $\mathrm{PdPh}_{4} \mathrm{TBP}$ was quenched by molecular oxygen (Figure 22 state of $\mathrm{PdPh}_{4} \mathrm{TBP}$ is generated by the 635-nm light $\mathrm{S}_{13}$ ). Because the DFT calculation suggests that the energy

excitation (green line in Figure 9a) 75 and it changes to a of the RPIC unit, the TTET from the perylene unit to the level of the $\mathrm{T}_{1}$ state of the perylene unit is lower than that spectrum with maxima at 495 and $640 \mathrm{~nm}$ (blue line) RPIC unit is energetically unfavourable (Table $\mathrm{S}_{5}-\mathrm{S}_{7}$ ). In

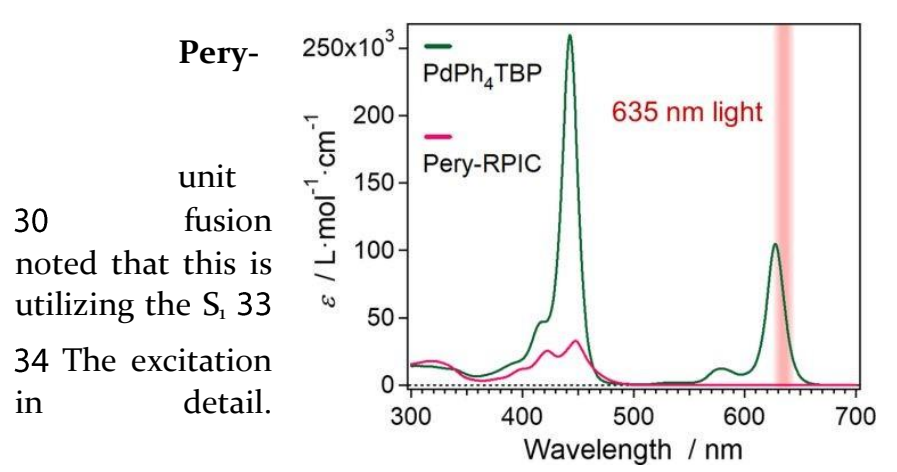

38 (a)

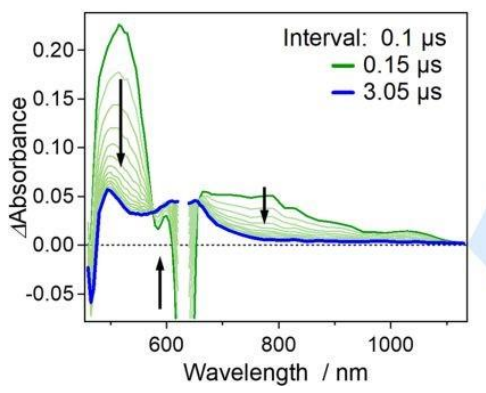

25 addition, it can be considered that the $\mathrm{C}-\mathrm{N}$ bond breaking 26 of RPIC would not proceed from the $\mathrm{T}_{1}$ state as 27 similar with hexaarylbiimidazole (HABI).77-79 Therefore, 28 the photochromic reaction of Pery-RPIC is proceeded via 29 the $\mathrm{S}_{1}$ state of the perylene generated by the triplet upconversion between the two triplet excited Pery31 RPIC. It should be the first example of 32 the efficient photochromic reaction directly state of the annihilator generated by the triplet fusion.

light intensity dependence of the 35 photochromic reaction is examined Generally, 36 the intensity of upconversion emission via triplet fusion 37 shows a change in the excitation light intensity

Figure 8. UV-vis absorption spectra of Pery-RPIC and dependence from quadratic to linear with increasing the $\mathrm{PdPh}{ }_{4} \mathrm{TBP}$ in toluene. excitation light intensity under the steady-state 40 condition..$^{80-82}$ It is expected that the amount of the

(b) Zoom Up

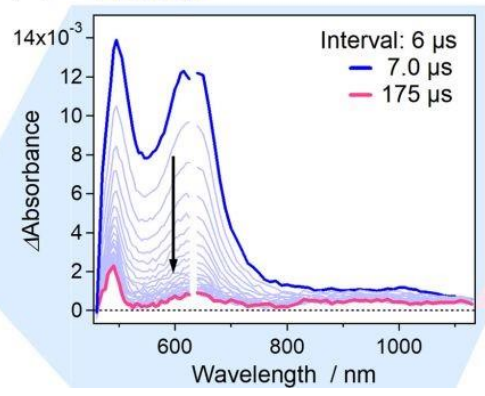

(c) Zoom Up

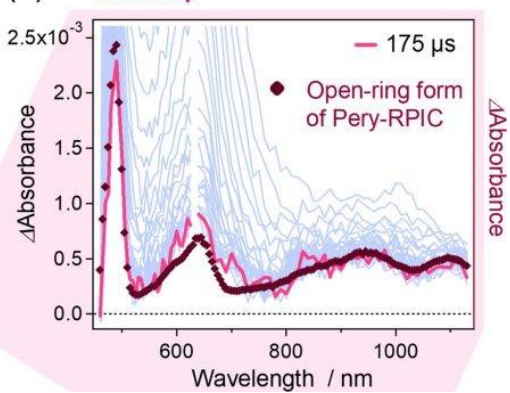

Figure 9. Transient absorption spectra of the mixture solution of Pery-RPIC $\left(10^{-3} \mathrm{M}\right)$ and $\mathrm{PdPh}_{4} \mathrm{TBP}\left(3 \times 10^{-5} \mathrm{M}\right)$ in degassed toluene (a) at $0.15-3.05 \mu \mathrm{s},(\mathrm{b}, \mathrm{c})$ at 7.0-175 $\mu$ s after the excitation with $635 \mathrm{~nm}$ nanosecond laser pulse (power $=2.7 \mathrm{~mJ} / \mathrm{pulse}$, pulse width $=5 \mathrm{~ns}$, at room temperature). (c) Black dot line shows the transient absorption spectrum of Pery-RPIC in toluene $\left(1.8 \times 10^{-5} \mathrm{M}\right)$ assigned to the open-ring form reached the thermal equilibrium between $\mathbf{B R}$ and $\mathbf{Q}\left(\lambda_{\text {ex. }}=450 \mathrm{~nm}\right.$, power $=6.2$ $\mathrm{mJ} /$ pulse, pulse width $=5 \mathrm{~ns}$, at $253 \mathrm{~K})$. 
spectra

Co., UV-

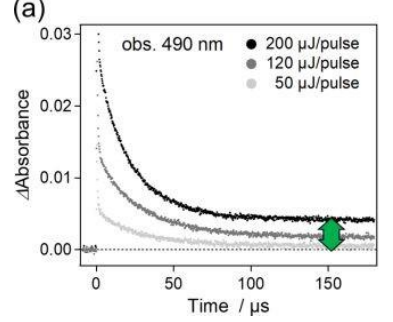

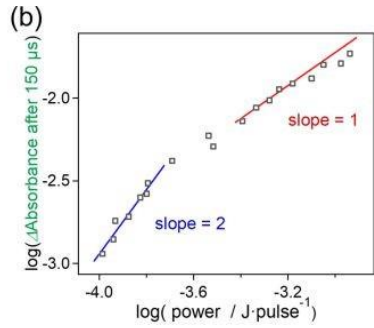

EXPERIMENTAL SECTION

Absorption and Fluorescence Spectroscopy. The absorption were measured by a UV-vis-NIR spectrophotometer (SHIMADZU 3600 Plus). The fluorescence spectra were recorded using a fluorescence spectrometer (HORIBA Ltd., FluoroMax3).

Transient Absorption Measurements in Microsecond Time Scale. The laser flash photolysis

9 experiments were carried out with a TSP-10oo time-

10 Figure 1o. (a) Kinetic traces of the transient absorbance resolved spectrophotometer (Unisoku). The excitation 11 observed at $490 \mathrm{~nm}$ after the irradiation with $635 \mathrm{~nm}$ laser pulse at $450 \mathrm{~nm}$ (pulse width $=5 \mathrm{~ns}$, frequency $=10 \mathrm{~Hz}$ ) was

12

13

14

15

16

17

18

19

pulse to the solution of Pery-RPIC (1.9 mM) and provided by a Continuum Surelite II Q-switched Nd:YAG laser coupled to a Continuum Panther EX OPO. The probe

$\mathrm{PdPh}_{4} \mathrm{TBP}(130 \mu \mathrm{M})$ in degassed toluene (pulse width $=5$ beam from a halogen lamp (OSRAM HLX64623) was used

ns, at room temperature). (b) Double logarithmic plots of the average of the transient absorbance at $490 \mathrm{~nm}$ during as the probe beam arranged in an orientation

150-180 $\mu \mathrm{s}$ after the excitation as a function of the perpendicular to the exciting laser beam. The probe beam excitation power. The blue and red lines are guide for slope was monitored with a photomultiplier tube (Hamamatsu

2 and 1, respectively. R2949) through a spectrometer (Unisoku MD2oo) for the

decay profile of the colored species. The excitation

photochromic product generated by nanosecond laser intensity of one pulse was estimated by an energy monitor 20 pulse irradiation also shows the similar excitation light (Gentec Electro-Optics MAESTRO). Optical-grade 21 intensity dependence (see Supporting Information). We solvents were used for all measurements.

22 measured the transient absorption spectra by varying the Transient Absorption Measurements in Picosecond 23 intensity of the excitation nanosecond laser pulse. Figure Time Scale. The femtosecond transient absorption spectra 24 10a shows the kinetic traces of the transient absorbance were recorded on the same setup reported earlier (see for 25 ( $\Delta$ Absorbance). $\Delta$ Absorbance at $150-$ $18 \mathrm{o} \mu \mathrm{s}$ is proportional example). ${ }^{83,84}$ The main laser source is a $1-\mathrm{kHz}$ Ti:sapphire 26 to the concentration of the open-ring form because the $\mathrm{T}_{1}$ laser system that delivered $100 \mathrm{fs}(1.1 \mathrm{~mJ})$ pulses at $800 \mathrm{~nm} .27$ states of $\mathrm{PdPh}_{4} \mathrm{TBP}$ and Pery-RPIC almost disappear 150 This beam was focused in a $1 \mathrm{~mm} \mathrm{CaF} 2$ rotating plate to

$28 \mu \mu$ after laser excitation. The plots of $\Delta$ Absorbance against generate white light continuum probe beam which was the excitation light intensity show the quadratic split into a probe beam and a reference beam. The pump30 dependence in the weak excitation region while it is close excitation pulses $(450 \mathrm{~nm}, \mathrm{FHWM} 0.4 \mathrm{~mm}$ at the to linear in the intense excitation light region (Figure 1ob). This change in the dependence can be described as the sample) were obtained from an OPA (Palitra, excel

transition from the second order reaction to the pseudo Continuum). The pump-probe polarization configuration 33 first one due to the high concentration of the $\mathrm{T}_{1}$ state of was set at the magic angle $\left(54.7^{\circ}\right)$ and the probe pulse was 
Pery-RPIC upon intense laser irradiation. delayed in time relative to the pump pulse using an optical

delay line (Microcontrol, precision: $0.1 \mu \mathrm{m}$ ). The

CONCLUSION transmitted light of the probe and reference beam was

We succeeded to demonstrate the red-light driven recorded on two different channels of a multichannel

photochromism via the triplet fusion of Pery-RPIC that spectrograph equipped with a CCD camera (Princeton 39 has a covalently bonded perylene as an annihilator unit. Instrument). A CuSO ${ }_{4}$ solution was placed in front of the 40 Because the energy level of the $T_{1}$ state of the annihilator is spectrograph to eliminate the remaining $800 \mathrm{~nm}$, and

lower than that of the photochromic unit, the TTET from Rayleigh scattered light from the pump beam was

the annihilator to the RPIC unit is inhibited. In addition, suppressed using a Notch filter (Semrock). The acquisition 43 the femtosecond time-resolved absorption and was control using a homemade LabVIEW program. Each

44 fluorescence spectroscopy for Pery-RPIC revealed that the time delay spectrum is the average of 3000 pump excitation. 45 introduction of the annihilator to the photochromic unit is The transient spectra were also computed with the same

highly efficient for the direct utilization of the excited program. The instrumental response function (IRF) of

singlet state of the annihilator to induce the photochromic about $140 \mathrm{ofs}$ was estimated measuring the stimulated

reaction. The mixture solution of $\mathrm{PdPh}_{4} \mathrm{TBP}$ and Pery Raman amplification signal from the solvent. All

RPIC shows the photochromic reaction of Pery-RPIC by experimental data were corrected from the group velocity

the irradiation of 635-nm light which cannot be directly dispersion wavelengths were fit using IgorPro and based on a global (GVD) and kinetic traces at different absorbed by Pery-RPIC. We revealed the photochromic analysis with three exponential functions and a constant reaction is induced via the triplet fusion from the transient convoluted with a Gaussian-shaped pulse of the IRF. absorption spectroscopy and the excitation light intensity

dependence. This molecular design will be also applied to

Samples were contained in $1 \mathrm{~mm}$ path length cell (Hellma,

$350 \mathrm{DL})$ and the absorbance was about 0.5 . The cell was the other photochromic molecules and will open up the moved continuously to avoid any thermal heating, development of the red or NIR light responsive molecules.

accumulation or photo-degradation. Stability of the sample was checked after each experiment.

Time-Resolved Fluorescence Measurements. The pulses and found to be about 1oo fs (FWHM). The fluorescence decays from 10 ps to nanosecond were fluorescence decays were thus analysed using a double measured using a timecorrelated single photon counting exponential decay convoluted with a Gaussian-shaped (TCSPC) technique picoquant. The details of the set up was FWHM of the IRF. The sample was placed in a 1-mm already described in details elsewhere. ${ }^{85}$ Here the cuvette with an optical density of 0.4 while the solution excitation pulse $(450 \mathrm{~nm}$ ) source was delivered by doubling was flown continuously to avoid photo-degradation effects. (harmonic generator, SHG, APE) a femtosecond Materials and Reagents. All of the reactions were

Ti:sapphire laser (9oo nm, Coherent Chameleon Ultra II, monitored by thin-layer chromatography carried out on $80 \mathrm{MHz}, 18 \mathrm{ofs}$ ) coupled to a pulse picker (4 MHz). $0.2 \mathrm{~mm}$ E. Merck silica gel plates (6oF-254). Column Fluorescence lifetimes were measured using an FT20o chromatography was performed on silica gel (silica gel 6oN, Picoquant spectrometer. The emission was collected Kanto Chemical Co., Inc.). NMR spectra were recorded at 
through a polarizer set at the magic angle and a Czerny $400 \mathrm{MHz}$ on a Bruker AVANCE III 400 NanoBay 12 Turner type monochromator (o.5 mm slit, bandpass $4 \mathrm{~nm}$ ) spectrometer. DMSO- $d_{6}$ and $\mathrm{CDCl}_{3}$ were used as 13 computer-controlled by the software from picoquant deuterated solvents. ESI-TOF-MS spectra were recorded

(picoharp). The single-photon events were collected by a on a Bruker micrOTOF II-AGA1 spectrometer. Unless cooled $\left(-40^{\circ}\right)$ microchannel plate photomultiplier tube otherwise noted, all of the reagents and reaction solvents R3809U (Hamamatsu) and recorded by a PicoHarp 300 were purchased from Tokyo Chemical Industry Co., Ltd., TCSPC card (PicoQuant). The instrumental response Wako Pure Chemical Industries, Ltd., Sigma-Aldrich Inc., 18 function was recorded using a Ludox solution, and its full Kanto Chemical Co., Inc., and AdipoGen Life Sciences Inc.,

width at half $\sim$ maximum ${ }^{4}$ number was 4 oof events ps. All reached decays at were the and used without further purification.

collected until the 1o Preparation of the Mixture Solution of Pery-RPIC

maximum. The recorded decays were analyzed by the and PdPh ${ }_{4}$ TBP for the Triplet Fusion. Pery-RPIC $\left(10^{-3} 22\right.$ FluoFit software (PicoQuant), i.e. decays were fitted by a M) in the sample solution is 100 times as concentrated as

sum of exponential functions convolved by the measured IRF. The quality of the fit was checked by the reduced $\chi^{2} \mathrm{PdPh}_{4} \mathrm{TBP}$ $\left(3 \times 10^{-5} \mathrm{M}\right)$ for the efficient triplet-triplet energy

(below 1.1), and the weighted residuals and autocorrelation transfer. ${ }^{87}$ The sample solution was degassed by freeze 25 function. Quality of the alignment was checked that the pump-thaw cycles in a Schlenk tube and transferred to a 26 decay of the coumarin 153 in acetonitrile can be fitted by a quartz cell (light path length: $1 \mathrm{~mm}$ ) in a globe box under 27 monoexponential function. nitrogen atmosphere. Optical-grade solvent was used for

the measurement.

Femtosecond and picosecond fluorescence decays were Synthesis. The synthetic procedure of Pery-RPIC is

measured using a femtosecond fluorescence upconversion 86 The source is a $1 \mathrm{kHz}$ Ti-Sapphire laser system shown in Scheme 2. 1-(3',5'-di-tertbutyl-4'-hydroxy-[1,1'-

setup.(Spitfire Pro 35F-XP, Spectra-Physics) that delivered 8 oo biphenyl]-2-yl)-2-phenylethane-1,2-dione (1) was

$\mathrm{nm}$ (4 mJ, 6o-nm bandwidth, FWHM), 35-fs pulses synthesized according to the literature procedures. ${ }^{65}$

(FWHM). The output of the amplifier is used to pump two 3,5-di-tert-butyl-2'-(2-(perylen-3-yl)-5-phenyl-1H-

identical two-stage optical parametric amplifiers (OPA) of imidazol-4-yl)-[1,1'-biphenyl]-4-ol (2). A suspension of 1 (301 35 white light continuum (Topas-C, Light Conversion) to get $\mathrm{mg}, 0.73 \mathrm{mmol}$ ), 3-perylenecalbaldehyde (225 $\mathrm{mg}$, $0.8 \mathrm{o}$ 36 the pump beam (magic angle configuration) at $450 \mathrm{~nm}$ $\mathrm{mmol}$ ) and ammonium acetate (1.69 g, $22 \mathrm{mmol}$ ) in acetic 37 (about $150 \mu \mathrm{J}$ at the sample, $60 \mathrm{fs}$ ). Less than 1 percent of acid ( $10 \mathrm{~mL}$ ) was stirred for $10 \mathrm{~h}$ at $110^{\circ} \mathrm{C}$ in a sealed tube. 38 the $800-n m$ amplifier output is used as gate pulses. The The reaction mixture was cooled to room temperature and 39 fluorescence light emitted from the sample was efficiently the mixture was neutralized by aqueous ammonia. The 
40 collected using an off-axis parabolic mirror, filtered to precipitate was filtered and washed with water and n41 suppress the scattered light, directed and overlapped with hexane, to give crude $2(524 \mathrm{mg})$ as an orange solid. The 42 the gate pulse (80o $\mathrm{nm}$, ca. $10 \mu \mathrm{J})$ in a BBO crystal. By crude product was used in next procedures without further 43 tuning the incident angle of these two beams relative to the purification because of the poor solubility.

44 crystal plane, the sum frequency of the fluorescence light Pery-RPIC. A solution of potassium ferricyanide (6.85 g, 45 and the gate pulse was generated. A photomultiplier tube $21 \mathrm{mmol}$ ), sodium hydroxide $(3.15 \mathrm{~g}, 56 \mathrm{mmol})$ in water ( 3746 (R1527, Hamamatsu), placed at the exit of a $\mathrm{mL}$ ) was added to a solution of $\mathbf{2}$ (crude product $500 \mathrm{mg}$ ) monochromator was used to detect the upconversion in benzene $(55 \mathrm{~mL})$. After stirring for $9 \mathrm{~h}$ at room fluorescence signal (heterodyne mode). The IRF was temperature, the resultant mixture was extracted with determined by cross-correlation between pump and gate benzene. The organic extract was washed with water and

\section{Scheme 2. Synthetic Scheme of Pery-RPIC}

brine, and filtered through a phase separator paper. After (5) Zhou, J.; Li, Y.; Tang, Y.; Zhao, F.; Song, X.; Li, E. Detailed removal of the solvents, the crude mixture was purified by Investigation on a Negative Photochromic Spiropyran. J. silica gel column chromatography (dichloromethane) Photochem. Photobiol. A 1995, 9o (2-3), 117-123.

followed by recrystallization from (6) Shiraishi, Y.; Itoh, M.; Hirai, T. Thermal Isomerization of Spiropyran to Merocyanine in Aqueous Media and Its dichloromethane/hexane, to give Pery-RPIC as a yellow Application to Colorimetric Temperature Indication. Phys. solid (431 mg, yield: 93 \% for two steps). ${ }^{1} \mathrm{H}$ NMR (400 MHz, Chem. Chem. Phys. 2010, 12 (41), 13737-13745.

DMSO- $\left.d_{6}\right) \delta: 8.41(\mathrm{~d}, J=7.72 \mathrm{~Hz}, 2 \mathrm{H}), 8.35(\mathrm{~d}, J=7.64 \mathrm{~Hz}$, (7) Parthenopoulos, D. A.; Rentzepis, P. M. Three-Dimensional $1 \mathrm{H}), 8.27$ $(\mathrm{d}, J=7.84 \mathrm{~Hz}, 1 \mathrm{H}), 8.00(\mathrm{~d}, J=7.32 \mathrm{~Hz}, 3 \mathrm{H}), 7.84$ Optical Storage Memory. Science 1989, 245 (4920), 843-845.

$8(\mathrm{t}, J=7.20 \mathrm{~Hz}, 2 \mathrm{H}), 7.73(\mathrm{~d}, J=8.36 \mathrm{~Hz}, 1 \mathrm{H}), 7.64(\mathrm{~d}, J=7.72$ (8) Irie, M.; Fukaminato, T.; Matsuda, K.; Kobatake, S. $9 \mathrm{~Hz}, 1 \mathrm{H}), 7.61-7.51(\mathrm{~m}$, $6 \mathrm{H}), 7.41(\mathrm{t}, J=7.42 \mathrm{~Hz}, 1 \mathrm{H}), 7.35(\mathrm{t}, J$ Photochromism of Diarylethene Molecules and Crystals: $10=7.62 \mathrm{~Hz}, 1 \mathrm{H}), 6.92(\mathrm{~d}, J=7.68 \mathrm{~Hz}, 1 \mathrm{H})$, $6.78(\mathrm{~s}, 2 \mathrm{H}), 0.85$ Memories, Switches, and Actuators. Chem. Rev. 2014, 114

11 (s, 18H). ${ }^{13} \mathrm{C} \mathrm{NMR}\left(400 \mathrm{~Hz}, \mathrm{CDCl}_{3}\right.$ ) $8: 185.29$, 147.78, 143.44, (9) (24), 12174-12277. Tsivgoulis G. M.; Lehn, J.-M. Photoswitched and 12 143.41, 136.73, 134.71, 134.61, 134.36, 134.19, 133.25, 133.15, 131.38, Functionalized Oligothiophenes: Synthesis and

13 131.01, 130.96, 130.62, 129.42, 128.98, 128.75, 128.52, 128.05, Photochemical and Electrochemical Properties. Chem. Eur. 14 $127.53,127.44,127.40,127.15,126.74,126.67,126.65,125.67, \quad J .1996,2$ (11), 1399-1406.

15 123.46, 120.81, 120.69, 120.59, 120.44, 118.25, 65.27, 34.85, (10) Jukes, R. T. F.; Adamo, V.; Hartl, F.; Belser P.; De Cola, L. 16 28.90. HRMS (ESI-TOF) calculated for $\mathrm{C}_{49} \mathrm{H}_{40} \mathrm{~N}_{2} \mathrm{O}[\mathrm{M}+\mathrm{H}]^{+}$: Photochromic Dithienylethene Derivatives Containing 17 673.3213, found: 673.3190. Ru(II) or Os(II) Metal Units. Sensitized Photocyclization

ASSOCIATED CONTENT (11) from a Triplet State.Fukaminato, T.; Hirose, T.; Doi, T.; Hazama, M.; Matsuda, Inorg. Chem. 20o4, 43 (9), 2779-2792.

K.; Irie, M. Molecular Design Strategy toward Diarylethenes 20 Supporting Information That Photoswitch with Visible Light. J. Am. Chem. Soc. 2014,

NMR spectra, ESI-TOF-MS spectra, HPLC charts and the $136(49), 17145^{-17154 .}$

other experimental details (PDF). This material is available (12) Honda, K.; Komizu, H.; Kawasaki, M. Reverse

free of charge via the Internet at http://pubs.acs.org. Photochromism of Stenhouse Salts. J. Chem. Soc., Chem.

(13) Commun.Helmy, S.; Leibfarth, F. A.; Oh, S.; Poelma, J. E.; Hawker, C. 1982, 253-254. 25 AUTHOR INFORMATION J.; Read De Alaniz, J. Photoswitching Using Visible Light: A 26 Corresponding Author New Class of Organic Photochromic Molecules. J. Am. Chem. *jiro_abe@chem.aoyama.ac.jp Soc. 2014, 136 (23), 8169-8172.

(14) Hemmer, J. R.; Poelma, S. O.; Treat, N.; Page, Z. A.; Dolinski, 29 Author Contributions N. D.; Diaz, Y. J.; Tomlinson, W.; Clark, K. D.; Hooper, J. P.;
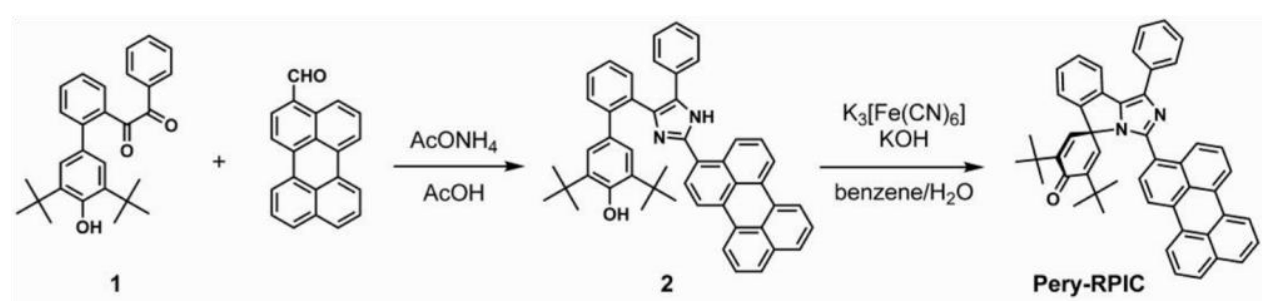
ACKNOWLEDGMENT 1910-1937.

The manuscript was written through contributions of all Hawker, C.; Read De Alaniz, J. Tunable Visible and Near Infrared Photoswitches. J. Am. Chem. Soc. 2016, 138 (42), authors. 13960-13966.

Notes (15) Lerch, M. M.; Szymański, W.; Feringa, B. L. The The authors declare no competing financial interest. (Photo)Chemistry of Stenhouse Photoswitches: Guiding Principles and System Design. Chem. Soc. Rev. 2018, 47 (6),

This work was supported in part by JSPS KAKENHI Grant (16) Hemmer, J. R.; Page, Z. A.; Clark, K. D.; Stricker, F.; Dolinski,

Numbers JP18Ho5263, JP26107010 in Scientific Research on N. D.; Hawker, C. J.; Read De Alaniz, J. Controlling Dark Equilibria and Enhancing Donor-Acceptor Stenhouse

Innovative Areas "Photosynergetics". The Chevreul Institute Adduct Photoswitching Properties through Carbon Acid 39 (FR 2638) and the Agence National de la Recherche (ANR-14 Design. J. Am. Chem. Soc. 2018, 140 (33), 10425-10429.

40 CEo8-oo15-o1 financial support. This work was also supported by the CNRS Ultrafast Nanoscopy) are acknowledged for (17) Yamashita, H.; Abe, J. Photochromic Properties of 41 LIA “Nano-synergetics”. [2.2]Increased Photosensitivity by Introducing Pyrenyl Moiety. ParacyclophaneBridged Imidazole Dimer with

42

REFERENCES (18) J. Phys. Chem. AHatano, S.; Horino, 2011, 115T.; (46), 13332-13337. Tokita, A.; Oshima, T.; Abe, J.

(1) Bléger, D.; Hecht, S. Visible-Light-Activated Molecular Unusual Negative Photochromism via a Short-Lived 45 Switches. Angew. Chem. Int. Ed. 2015, 54 (39), 11338-11349. Imidazolyl Radical of 1,1'-Binaphthyl-Bridged Imidazole 46 (2) Siewertsen, R.; Neumann, H.; Buchheimstehn, B.; Herges, Dimer. J. Am. Chem. Soc. 2013, 135 (8), 3164-3172.

R.; Na, C. Highly Efficient Reversible Z-E (19) Yamaguchi, T.; Kobayashi Y.; Abe, J. Fast Negative

Photoisomerization of a Bridged Azobenzene with Visible Light through Resolved $\mathrm{S}_{1}\left(\mathrm{n} \pi^{*}\right)$ Absorption Bands. J. Am. Photochromism Imidazolyl Radical Complex. of 1,1'-Binaphthyl-Bridged J. Am. Chem. Soc. 2016Phenoxyl, 138 (3),

Chem. Soc. 2009, 131 (43), 15594-15595. 906-913.

(3) Beharry, A. A.; Sadovski, O.; Woolley, G. A. Azobenzene (2o) Ikezawa, T.; Mutoh, K.; Kobayashi, Y.; Abe, J. ThiophenePhotoswitching without Ultraviolet Light. J. Am. Chem. Soc. Substituted Phenoxyl-Imidazolyl Radical Complexes with

2011, 133 (49), 19684-19687. High Photosensitivity. Chem. Commun. 2016, 52 (12), 2465- (4) Bléger, D.; Schwarz, J.; Brouwer, A. M.; Hecht, S. o 2468.

Fluoroazobenzenes as Readily Synthesized Photoswitches (21) Kobayashi, Y.; Katayama, T.; Yamane, T.; Setoura, K.; Ito, S.; Offering Nearly Quantitative Two-Way Isomerization with Miyasaka H.; Abe, J. Stepwise Two-Photon Induced Fast

Visible Light. J. Am. Chem. Soc. 2012, 134 (51), 20597-206oo.

Photoswitching Via Electron Transfer in Higher Excited States of Photochromic Imidazole Dimer. J. Am. Chem. Soc. 2016, 138 (18), 5930-5938.

(22) Yonekawa, I.; Mutoh, K.; Kobayashi, Y.; Abe, J. Intensity Singlet-to-Triplet Absorption. Acc. Chem. Res. 2017, 50 (10), Dependent Photoresponse of Biphotochromic Molecule 2487-2495.

Composed of a Negative and a Positive Photochromic Unit. $\quad$ (41) Dou, Q.; Jiang, L.; Kai, D.; Owh, C.; Jun Loh, X. Bioimaging J. Am. Chem. Soc. 2018, 140 (3), 1091-1097. and Biodetection Assisted with TTA-UC Materials. Drug,

(23) Yonekawa, I.; Mutoh, K.; Abe, J. Visible Light Intensity Discov. Today 2017, 22 (9), 1400-1411. Dependent Negative Photochromism of Binaphthyl (42) Askes, S. H. C.; Bonnet, S. Solving the Oxygen Sensitivity of Bridged Phenoxyl-Imidazolyl Radical Complex. Chem. Sensitized Photon Upconversion in Life Science Commun. 2019, 55 (9), 1221-1224. Applications. Nat. Rev. Chem. 2018, 2, 437-452.

(24) Mutoh, K.; Miyashita, N.; Arai, K.; Abe, J. Turn-On Mode （43） Joarder, B.; Yanai, N.; Kimizuka, N. Solid-State Photon 
8 Fluorescence Switch by Using Negative Photochromic Upconversion Materials: Structural Integrity and Triplet- 9 Imidazole Dimer. J. Am. Chem. Soc. 2019, 141 (14), 5650-5654. Singlet Dual Energy Migration. J. Phys. Chem. Lett. 2018, 910 (25) Yang, Y.; Hughes, R. P.; Aprahamian, I. Visible Light (16), 4613-4624.

Chem. Soc. Switching of 2012a, BF 1342- (37), 15221-15224. Coordinated Azo Compound. J. Am. (44) Emission Pun, A. B.; from Campos, Triplet L. M.; Fusion Congreve, Upconversion D. N. Tunable in

(26) Fukunishi, K.; Tatsuma, M.; Fatah Ur Rahman, S. M.; Diketopyrrolopyrroles. J. Am. Chem. Soc. 2019, 141 (9), 3777Kuwabara, M.; Yamanaka, H.; Nomura, M. Cis/Trans 3781. Isomerization of Thioindigo Derivatives Adsorbed on Silica (45) Pawlicki, M.; Collins, H. A.; Denning, R. G.; Anderson, H. L. 15 Gel Modified with Octadecyl Groups. Bull. Chem. Soc. Jpn. Zweiphotonenabsorption Und Das Design von 16 2006, 63 (12), $3701-3703$. Zweiphotonenfarbstoffen. Angew. Chem. 2009, 121 (18),

(27) Huang, C. Y.; Bonasera, A.; Hristov, L.; Garmshausen, Y.; 3292-3316.

Schmidt, B. M.; Jacquemin, D.; Hecht, S. Indigos as Readily Available Red-Light Photoswitches with N,N'-Disubstituted (46) Chem. Int. Ed.Haase, M.; Schäfer, H. Upconverting Nanoparticles. 2011, 50 (26), 5808-5829. Angew.

Tunable Thermal Half-Lives. J. Am. Chem. Soc. 2o17, 139 (42), (47) Liu, Y.; Lu, Y.; Yang, X.; Zheng, X.; Wen, S.; Wang, F.; Vidal, 15205-15211. X.; Zhao, J.; Liu, D.; Zhou, Z.; Ma, C.; Zhou, J.; Piper, J. A.; Xi,

(28) Petermayer, C.; Dube, H. Indigoid Photoswitches: Visible P.; Jin, D. Amplified Stimulated Emission in Upconversion 22 Light Responsive Molecular Tools. Acc. Chem. Res. 2018, 51 Nanoparticles for Super-Resolution Nanoscopy. Nature 543,

(5), 1153-1163. 229-233.

(29) R. Blattmann, H. R.; Meuche, D.; Heilbronner, E.; Molyneux, J.; Boekelheide, V. Photoisomerization of Trans-15,16 (48) T.; Blauschev, S.; Yakutkin, V.; Wegner, G.; Minch, B.; Miteva, Nelles, G.; Yasuda, A. Two Pathways for Photon

Dimethyldihydropyrene. J. Am. Chem. Soc. 1965, 87 (1), 130- Upconversion in Model Organic Compound Systems. J. Appl.

131. Phys. 2007, 101, 023101.

(30) Bohne, C.; Mitchell, R. H. Characterization of the (49) Boyer, J.-C.; Carling, C.-J.; Gates B. D.; Branda, N. R. Two28 Photochromism of Dihydropyrenes with Photophysical Way Photoswitching Using One Type of Near-Infrared 29 Techniques. J. Photochem. Photobiol. C 2011, 12 (2), 126-137. Light, Upconverting Nanoparticles, and Changing Only the

(31) Photochromism Klaue, K.; Garmshausen, beyond Visible: Y.; Direct Hecht, One-Photon S. Taking NIR (50) Light Intensity. Yan, B.; Boyer, J.-C.; Branda N. R.; Zhao, Y. Near-Infrared J. Am. Chem. Soc. 2010, 132 (44), 15766-15772.

Photoswitches Operating in the Biological Window. Angew. Light-Triggered Dissociation of Block Copolymer Micelles 32 Chem. Int. Ed. 2018, 57 (5), 1414-1417. Using Upconverting Nanoparticles. J. Am. Chem. Soc., 2o11, 33 (32) Parker, C. A.; Hatchard, C. G. Delayed Fluorescence from 133 (49), 19714-19717.

Solutions of Anthracene and Phenanthrene. Proc. R. Soc. (51) Khnayzer, R. S.; Blumhoff, J.; Harrington, J. A.; Haefele, A.; Lond. A 1962, 269 (1339), 574-584. Deng, F.; Castellano, F. N. Upconversion-Powered (33) Birks, J. B. The Quintet State of the Pyrene Excimer. Phys. Photoelectrochemistry. Chem. Commun. 2012, 48 (2), 209-

(34) Lett.Islangulov, R. R.; Kozlov, D. V.; Castellano, F. N. Low Power 1967, 24 A (9), 479-48o. (52) 211. Jiang, Z.; Xu, M.; Li, F.; Yu, Y. Red-Light-Controllable

Upconversion Using MLCT Sensitizers. Chem. Commun. Liquid-Crystal Soft Actuators via Low-Power Excited 2005, 1 (30), 3776-3778. Upconversion Based on Triplet-Triplet Annihilation. J. Am.

(35) Baluschev, S.; Miteva, T.; Yakutkin, V.; Nelles, G.; Yasuda, Chem. Soc. 2o13, 135 (44), 16446-16453. A.; Wegner, G. Up-Conversion Fluorescence: Noncoherent (53) Askes, S. H. C.; Bahreman, A.; Bonnet, S. Activation of a 42 Excitation by Sunlight. Phys. Rev. Lett. 20o6, 97 (14), 7-9. Photodissociative Ruthenium Complex by Triplet-Triplet

(36) Upconversion Singh-Rachford, Based T. N.; on Castellano, Sensitized F. Triplet-Triplet N. Photon Annihilation Upconversion in Liposomes. Ed. 2014, 53 (4), 1029-1033. Angew. Chem. Int.

Annihilation. Coordin. Chem. Rev. 2010, 254 (21-22), 256o- (54) Cui, X.; Zhao, J.; Zhou, Y.; Ma, J.; Zhao, Y. Reversible 
2573. Photoswitching of Triplet-Triplet Annihilation $46 \quad$ (37) Simon, Y. C.; Weder, C. Low-Power Photon Upconversion Upconversion Using Dithienylethene Photochromic 47 Through Triplet-Triplet Annihilation in Polymers. J. Mater. Switches. J. Am. Chem. Soc. 2014, 136 (26), 9256-9259.

48 Chem. C 2012, 22 (39), 20817-2083o. (55) Majek, M.; Faltermeier, U.; Dick, B.; Pérez-Ruiz, R.; Jacobi 49 (38) Monguzzi, A.; Tubino, R.; Hoseinkhani, S.; Campione, M.; von Wangelin, A. Application of Visible-to-UV Photon

50 Meinardi, F. Low Power, Non-Coherent Sensitized Photon up-Conversion: Modelling and Perspectives. Phys. Chem. Upconversion Aryl Bromides. to Chem. Eur. J.Photoredox 2015Catalysis: , 21 (44), 15496-15501. The Activation of

Chem. Phys. 2012, 14 (13), 4322-4332. （56) Häring, M.; Pérez-Ruiz, R.; Von Wangelin, A. J.; Díaz, D. D.

(39) Zhou, J.; Liu, Q.; Feng, W.; Sun, Y.; Li, F. Upconversion Intragel Photoreduction of Aryl Halides by Green-to-Blue Luminescent Materials: Advances and Applications. Chem. Upconversion under Aerobic Conditions. Chem Commun. Rev. 2015, 115 (1), 395-465. 2015, 51 (94), 16848-16851.

(40) Yanai, N.; Kimizuka, N. New Triplet Sensitization Routes for (57) Ravetz, B. D.; Pun, A. B.; Churchill, E. M.; Congreve, D. N.; Photon Upconversion: Thermally Activated Delayed Rovis, T.; Campos, L. M. Photoredox Catalysis Using Fluorescence Molecules, Inorganic Nanocrystals, and Infrared Light via Triplet Fusion Upconversion. Nature 2019, 565 (7739), 343-346.

(58) Vinogradov, S. A.; Wilson, D. F. Shell Biradical in Photochromic Radical Dimer. J. Am. Chem. Metallotetrabenzoporphyrins. New Phosphorescent Probes Soc. 2017, 139 (18), 6382-6389.

for Oxygen Measurements. J. Chem. Soc., Perkin Trans. $2 \quad$ (75) $\quad$ Cui, $\quad$ X.; $\quad$ Zhao, $\quad$ J.; $\quad$ Yang, P.;

Sun, J. Zinc(Ii)

1995, 103-111. Tetraphenyltetrabenzoporphyrin Complex as Triplet (59) Rogers, J. E.; Nguyen, K. A.; Hufnagle, D. C.; McLean, D. G.; Photosensitizer for Triplet-Triplet Annihilation Su, W.; Gossett, K. M.; Burke, A. R.; Vinogradov, S. A.; Upconversion. Chem. Commun. 2013, 49 (87), 10221-10223.

Pachter, R.; Fleitz, P. A. Observation and Interpretation of (76) Porter, G.; Windsor, M. W. The Triplet State in Fluid Media. Annulated Porphyrins: Studies on the Photophysical Proc. R. Soc. Lond. A 1958, 245 (1241), 238-258.

Properties of Meso-Tetraphenylmetalloporphyrins. J. Phys. (77) Qin, X. Z.; Liu, A.; Trifunac, A. D.; Krongauz, V. V. 8 Chem. A 2oo3, Photodissociation of Hexaarylbiimidazole. 1. Triplet-State

9 (6o) Baluschev, S.; Yakutkin, V.; Miteva, T.; Wegner, G.; Roberts, $\quad$ Formation. J. Phys. Chem. 1991, 95 (15), $5822-5826$.

10 T.; Nelles, G.; Yasuda, A.; Chernov, S.; Aleshchenkov, S.; (78) Liu, A. D.; Trifunac, A. D.; Krongauz, V. V.

Cheprakov, Excited Annihilation A. A General Up-Conversion: Approach for Transforming Non-Coherently the Photodissociation Sensitized Dissociation. of Hexaarylbiimidazole. J. Phys. Chem. 1992, 962. (1), 207-211. Direct and

Solar-Spectrum. New J. Phys. 20o8, 10, 013007. (79) Lin, Y.; Liu, A.; Trifunac, A. D.; Krongauz, V. V. Investigation 13 (61) Murakami, Y. Photochemical Photon Upconverters with of Electron Transfer between Hexaarylbiimidazole and 14 Ionic Liquids. Chem. Phys. Lett. 2011, 516 (1-3), 56-61. Visible Sensitizer. Chem. Phys. Lett. 1992, 198 (1-2), 200-206.

15 (62) Hoseinkhani, S.; Tubino, R.; Meinardi, F.; Monguzzi, A. (8o) Monguzzi, A.; Mézyk, J.; Scotognella, F.; Tubino, R.; 16 Achieving the Photon Up-Conversion Thermodynamic Meinardi, F. Upconversion-Induced Fluorescence in

\section{Yield Upper Limit by Sensitized Triplet-Triplet Multicomponent Systems: Steady-State Excitation Power}

Annihilation. 4024. Phys. Chem. Chem. Phys. 2015, 17 (6), 4020- (81) Threshold. Monguzzi, A.; Tubino, R.; Hoseinkhani, S.; Campione, M.; Phys. Rev. B 20o8, 78 (19), 2-6.

(63) Sasaki, Y.; Amemori, S.; Kouno, H.; Yanai, N.; Kimizuka, N. Meinardi, F. Low Power, Non-Coherent Sensitized Photon 20 Near Infrared-to-Blue Photon Upconversion by Exploiting Up-conversion: Modelling and Perspectives. Phys. Chem. 21 Direct S-T Absorption of a Molecular Sensitizer. J. Mater. Chem. Phys. 2012, 14 (13), 4322-4332.

Chem. C 2017, 5 (21), 5063-5067. (82) Kamada, K.; Sakagami, Y.; Mizokuro, T.; Fujiwara, Y.;

(64) Yamashita, H.; Ikezawa, T.; Kobayashi, Y.; Abe, J. Kobayashi, K.; Narushima, K.; Hirata, S.; Vacha, M. Efficient

Photochromic with Decoloration Phenoxyl-Imidazolyl Rates from Tens Radical of Nanoseconds Complexes to Triplet-Triplet Crystalline Solids Annihilation Fabricated: Upconversion Via Solution Casting in Binary and

Seconds. J. Am. Chem. Soc. 2015, 137 (15), 4952-4955. $\quad$ Operated in Air. Mater. Horiz. 2017, 4 (1), 83-87.

(65) Kobayashi, Y.; Shima, K.; Mutoh, K.; Abe, J. Fast (83) Colletier, J. P.; Sliwa, M.; Gallat, F. X.; Sugahara, M.; Guillon, 27 Photochromism Involving Thermally-Activated Valence V.; Schirò, G.; Coquelle, N.; Woodhouse, J.; Roux, L.; 28 Isomerization of 
Phenoxyl-Imidazolyl Radical Complex Gotthard, G.; Royant, A.; Uriarte, L. M.; Ruckebusch, C.; Joti, 29 Derivatives. J. Phys. Chem. Lett. 2016, 7 (16), 3067-3072. Y.; Byrdin, M.; Mizohata, E.; Nango, E.; Tanaka, T.; Tono, K.;

(66) Valence Tokunaga, A.; Mutoh, K.; Hasegawa, T.; Abe, J. Reversible Photoisomerization between Closed-Shell Yabashi, Bourgeois, M.; D.; Adam, Weik, V.; Cammarata, M. Serial M.; Schlichting, Femtosecond I.;

41 (7o) Goldschmidt, C. R.; Ottolenghi, M. Laser Photolysis of Sliwa, M.; Didier, P. Emission Properties of Oxyluciferin and 42 Perylene Solutions. J. Phys. Chem. 1971, 75 (25), 3894-3897. Its Derivatives in Water: Revealing the Nature of the

Quinoidal and Open-Shell Biradical Forms. J. Phys. Chem. Crystallography and Ultrafast Absorption Spectroscopy of Lett. 2018, 9 (8), 1833-1837. the Photoswitchable Fluorescent Protein IrisFP. J. Phys.

(67) Toshimitsu, S.; Shima, K.; Mutoh, K.; Kobayashi, Y.; Abe, J. $\quad$ Chem. Lett. 2016, 7 (5), 882-887.

Rational Molecular Designs for Controlling (84) Sliwa, M.; Mouton, N.; Ruckebusch, C.; Poisson, L.; Idrissi, 35 Photochromism: Thermally Activated Valence A.; Alö̈se, S.; Potier, L.; Dubois, J.; Poizat, O.; Buntinx, G.

Isomerization of Phenoxyl-Imidazolyl Radical Complexes. Investigation of Ultrafast Photoinduced Processes for

(68) ChemPhotoChemSimmons, H. E.; 2o19Fukunaga, , 3 (6), 487-494. T. Spiroconjugation. J. Am. Salicylidene Aniline in Solution and Gas Phase: Toward a General Photo-Dynamical Scheme. Photochem. Photobiol.

Chem. Soc. 1967, 89(20), 5208-5215. Sci. 2010, 9 (5), 661-669.

(69) Hoffmann, R.; Imamura, A.; Zeiss, G. D. Spirarenes. J. Am. (85) Ghose, A.; Rebarz, M.; Maltsev, O. V.; Hintermann, L.; 40 Chem. Soc. 1967, 89(20), 5215-5220. Ruckebusch, C.; Fron, E.; Hofkens, J.; Mély, Y.; Naumov, P.;

(71) Absorption/Gain Meyer, Y. H.; Plaza, Spectroscopy P. Ultrafast of Perylene Excited Singlet in Solution. State Emissive Species in Firefly Bioluminescence. B 2015, 119 (6), 2638-2649. J. Phys. Chem.

Chem. Phys. 1995, 200 (1-2), 235-243. (86) Chong, H.; Fron, E.; Liu, Z.; Boodts, S.; Thomas, J.; Harvey, 45 (72) Satoh, Y.; Ishibashi, Y.; Ito, S.; Nagasawa, Y.; Miyasaka, H.; J. N.; Hofkens, J.; Dehaen, W.; Van der Auweraer, M.; Smet,

46 Chosrowjan, H.; Taniguchi, S.; Mataga, N.; Kato, D.; Kikuchi, M. Acid-Sensitive BODIPY Dyes: Synthesis through Pd47 A.; Abe, J. Direct Observation of the Ultrafast Evolution of Catalyzed Direct C $\left(\mathrm{sp}^{3}\right)$ - H Arylation and Photophysics. 48 Open-Shell Biradical in Photochromic Radical Dimer. Chem. Chem. Eur. J. 2017, 23 (19), 4687-4699.

Phys. Lett. 2007, 448 (4-6), 228-231. (87) Hoseinkhani, S.; Tubino, R.; Meinardi, F.; Monguzzi, A.

(73) Taniguchi, S.; Chosrowjan, H.; Mataga, N.; Kato, D.; Kikuchi, Miyasaka, H.; Satoh, Y.; Ishibashi, Y.; Ito, S.; Nagasawa, Y.; Achieving Yield Upper Limit by Sensitized Triplet-Triplet Annihilation. the Photon Up-Conversion Thermodynamic

A.; Abe, J. Ultrafast Photodissociation Dynamics of a Phys. Chem. Chem. Phys. 2015, 17 (6), 4020-4024. Hexaarylbiimidazole Derivative with Pyrenyl Groups: Dispersive Reaction from Femtosecond to 10 ns Time Regions. J. Am. Chem. Soc. 2009, 131 (21), 7256-7263.

(74) Kobayashi, Y.; Okajima, H.; Sotome, H.; Yanai, T.; Mutoh, K.; Yoneda, Y.; Shigeta, Y.; Sakamoto, A.; Miyasaka, H.; Abe, J. Direct Observation of the Ultrafast Evolution of Open-

TOC

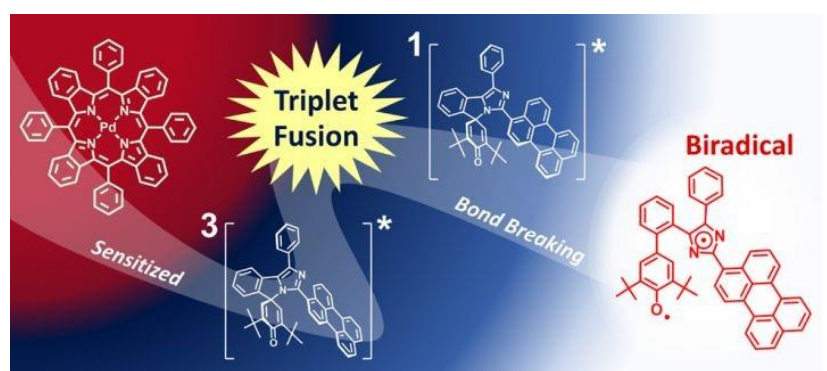


34

35

36

37

38

39

40

41

42

43

44

45

46

47

48

49

50 
(a)

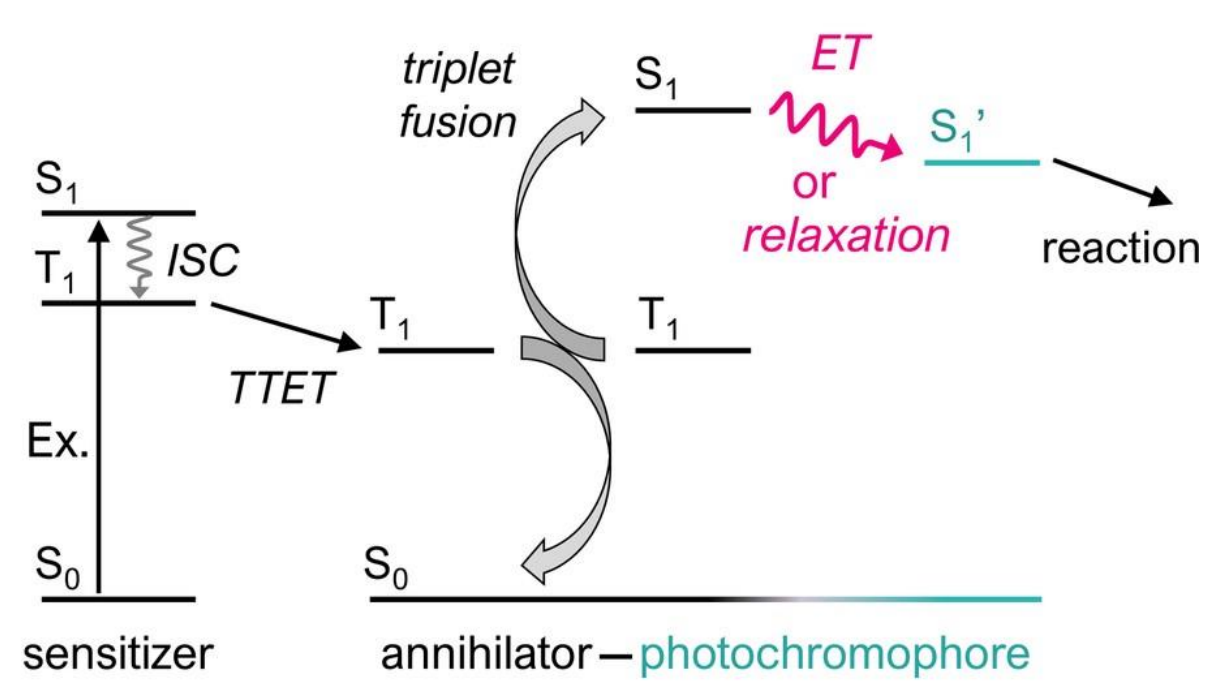

(b)

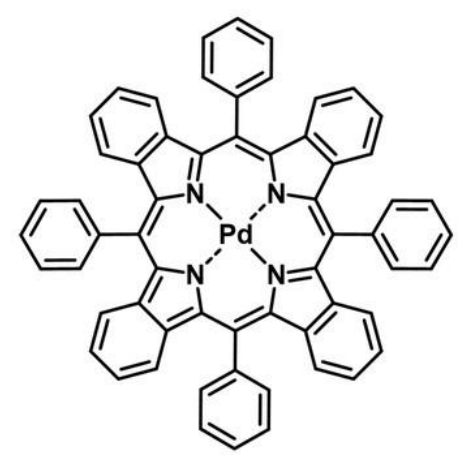

$\mathrm{PdPh}_{4}$ TBP

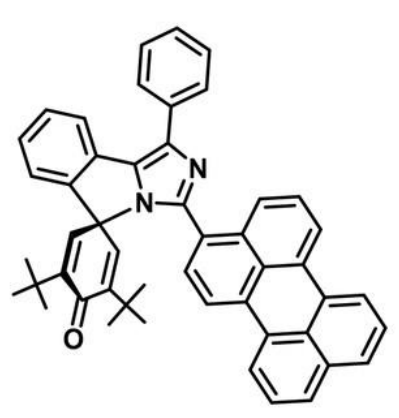

Pery-RPIC

Figure 1 


\section{Page 13 of 24 Journal of the American Chemical Society}

1
2
3
4
5
6
7
8
9
10
11
12
13
14
15
16
17
18
19
20
21
22
23
24
25
26
27
28
29
30
31
32
33
34
35
36
37
38
39
40
41
42
43
45

Figure 2

$84 \times 36 \mathrm{~mm}(300 \times 300$ DPI)

24

25

28

29

30

31

32

34

35

36 (a)

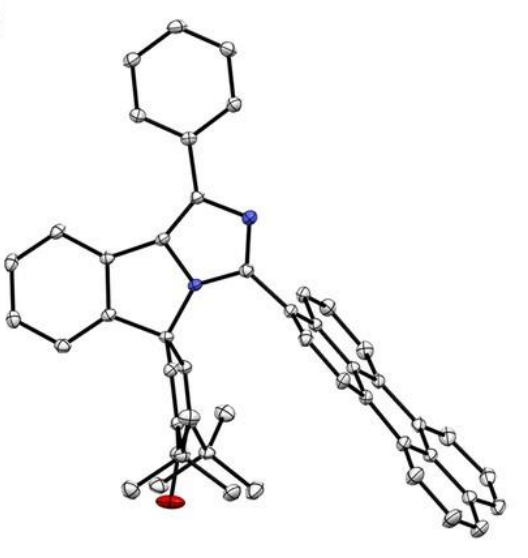

(b)

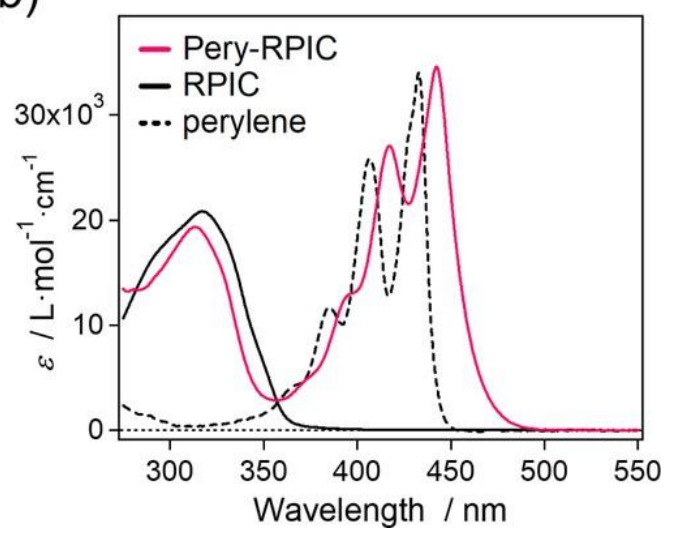


53

54

55

56

57

58

59

60

ACS Paragon Plus Environment 
(a)

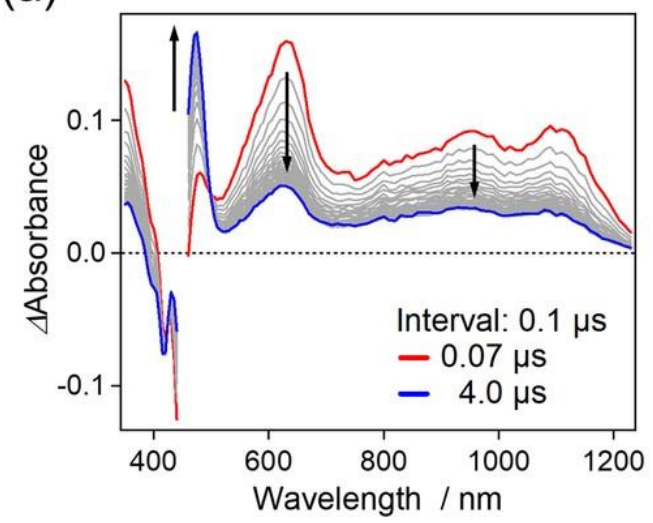

(b)

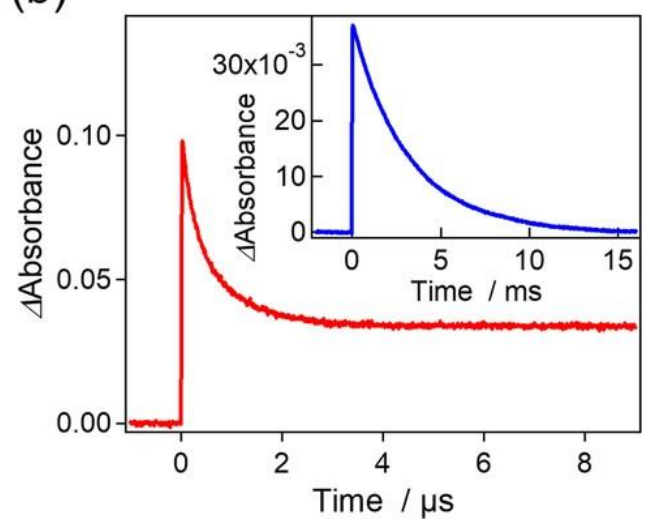

Figure 3

$84 \times 35 \mathrm{~mm}(300 \times 300$ DPI $)$ 
Page 15 of 24 Journal of the American Chemical Society

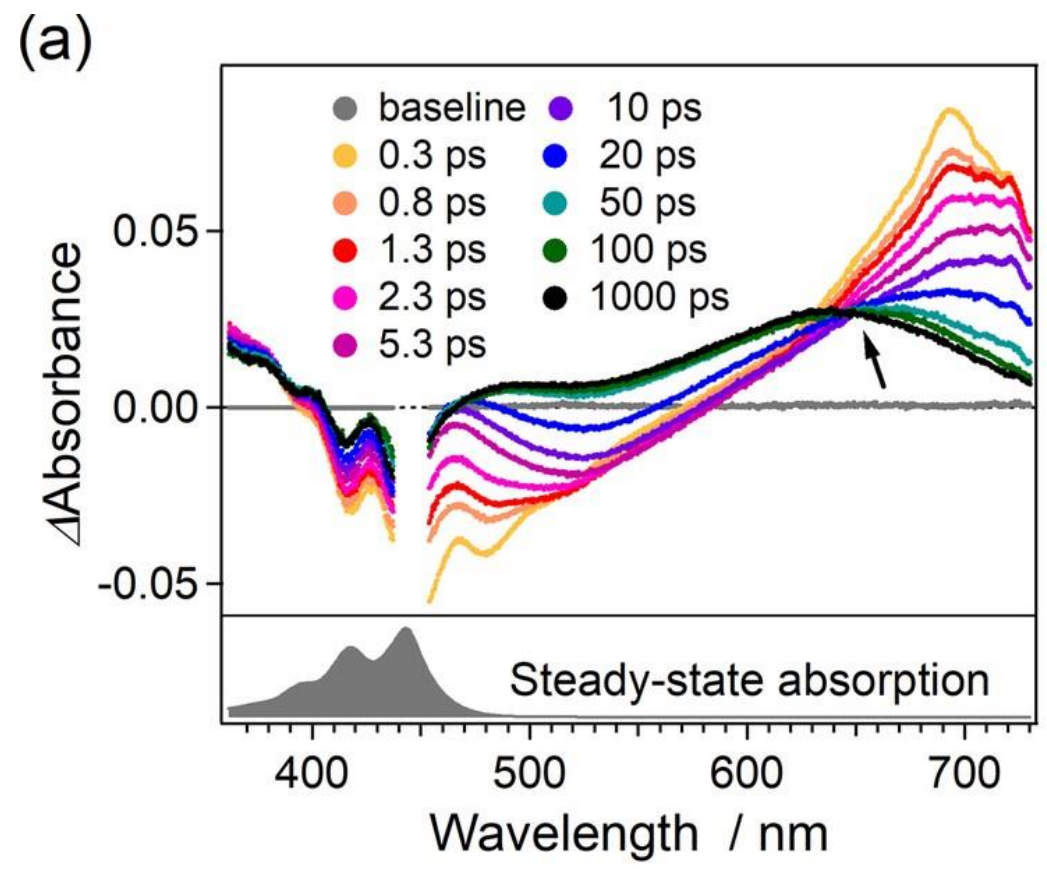

(b)

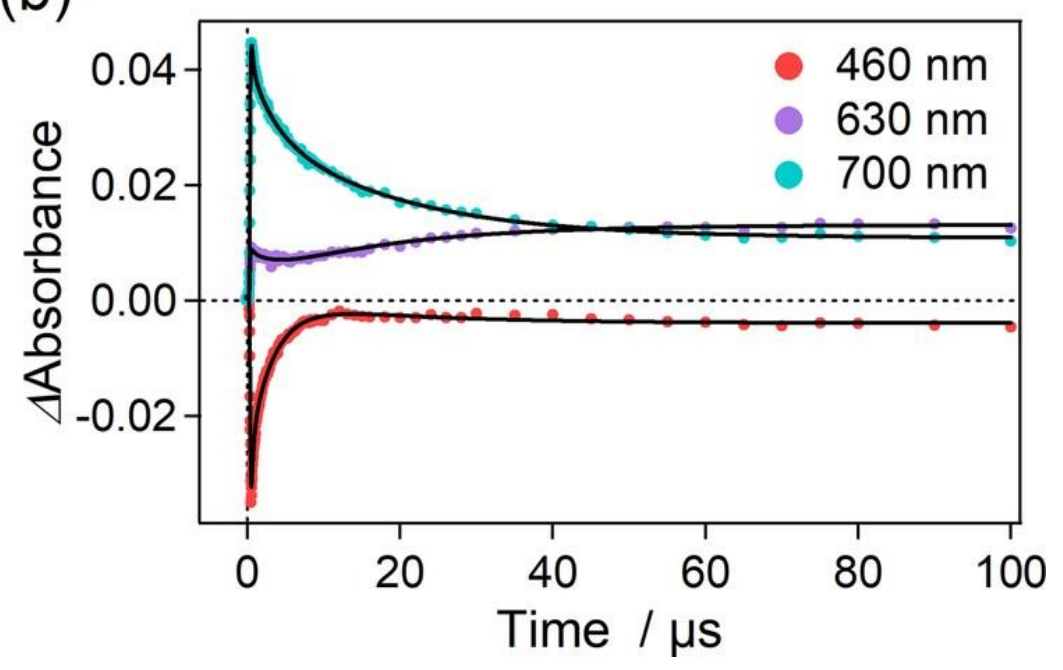

Figure 4 


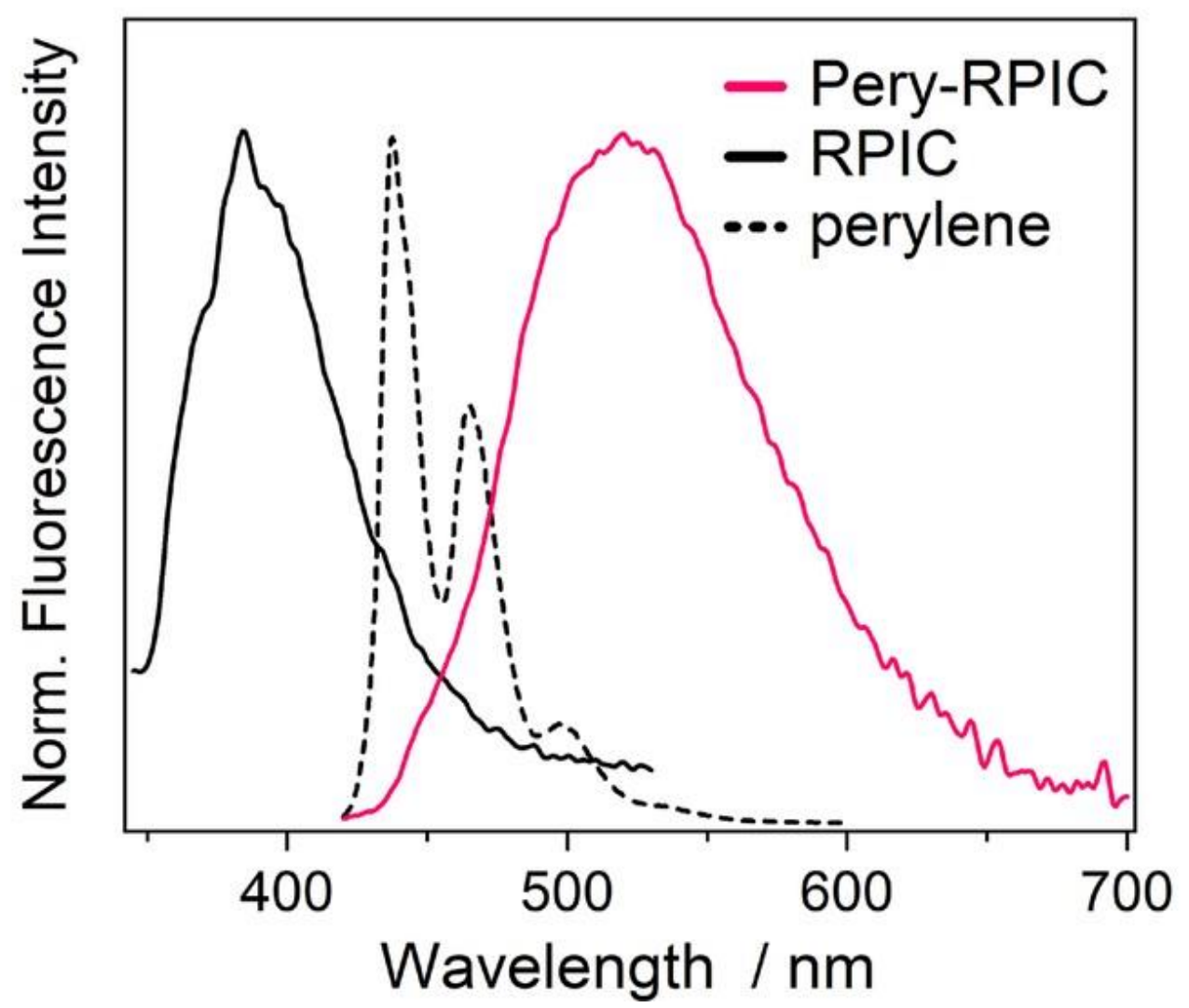

4

Figure 5

$56 \times 47 \mathrm{~mm}(300 \times 300$ DPI $)$ 
Page 17 of 24 Journal of the American Chemical Society

1
2
3
4
5
6
7
8
9
10
11
12
13
14
15
16
17
18
19
20
21
22
23
24
25
26
27
28
29
46
30
31
32
33
34
35
36
37
38
39
40
41

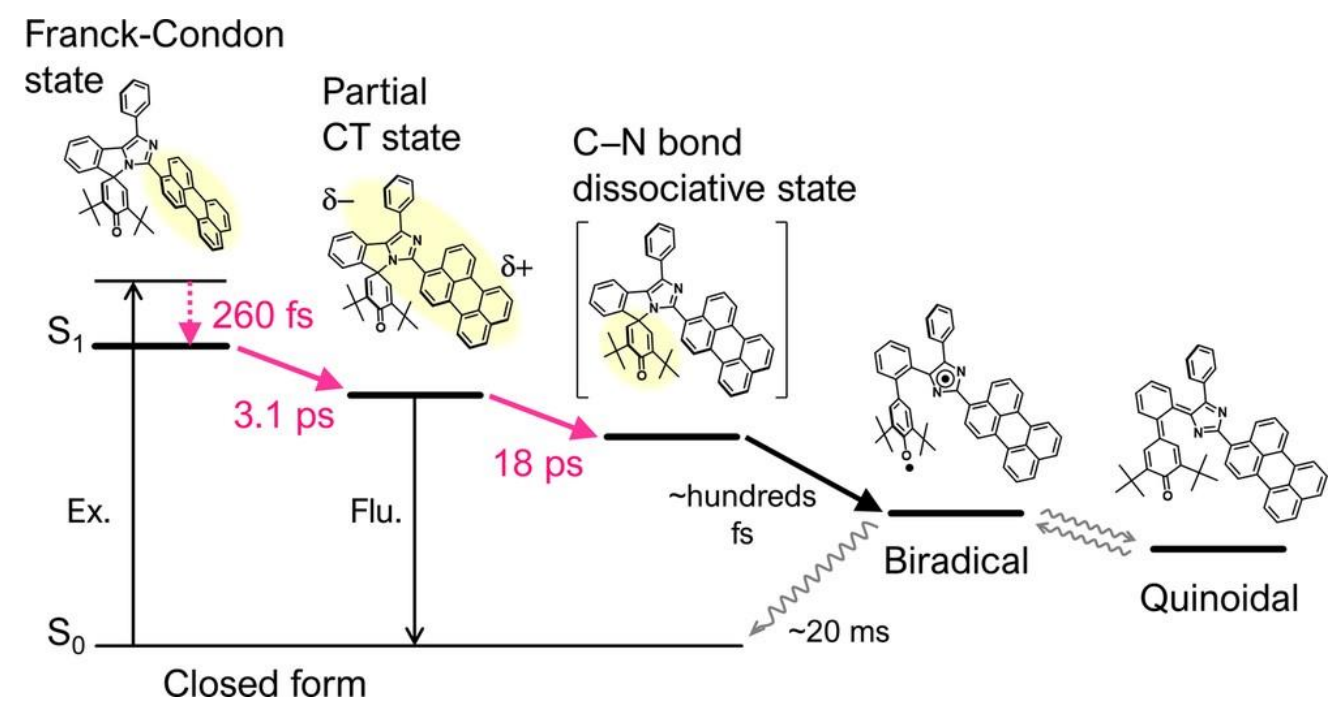

Figure 6

$84 \times 44 \mathrm{~mm}(300 \times 300$ DPI $)$ 
53

54

55

56

57

58

59

60

ACS Paragon Plus Environment 


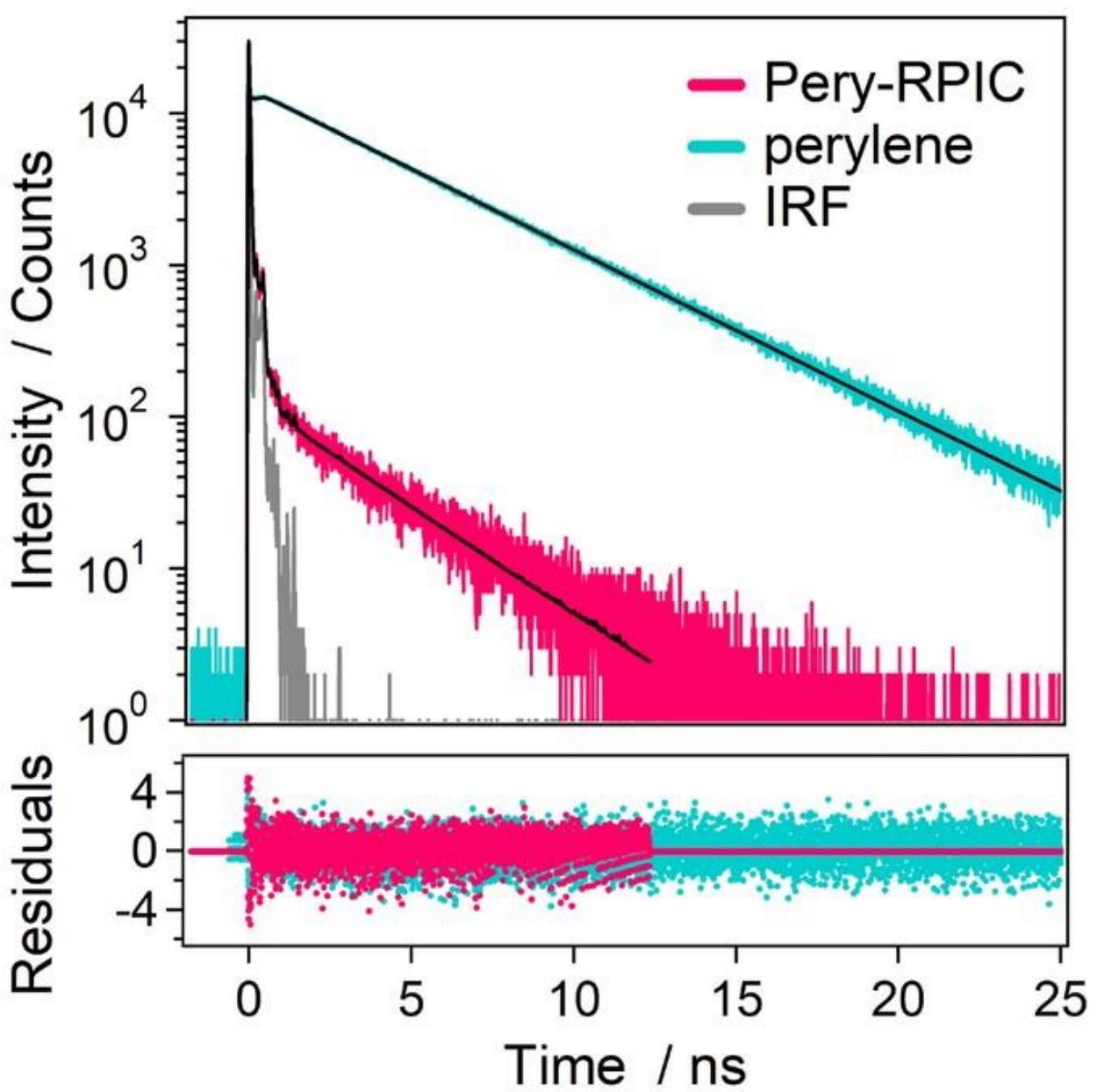

Figure 7 
Page 19 of 24 Journal of the American Chemical Society

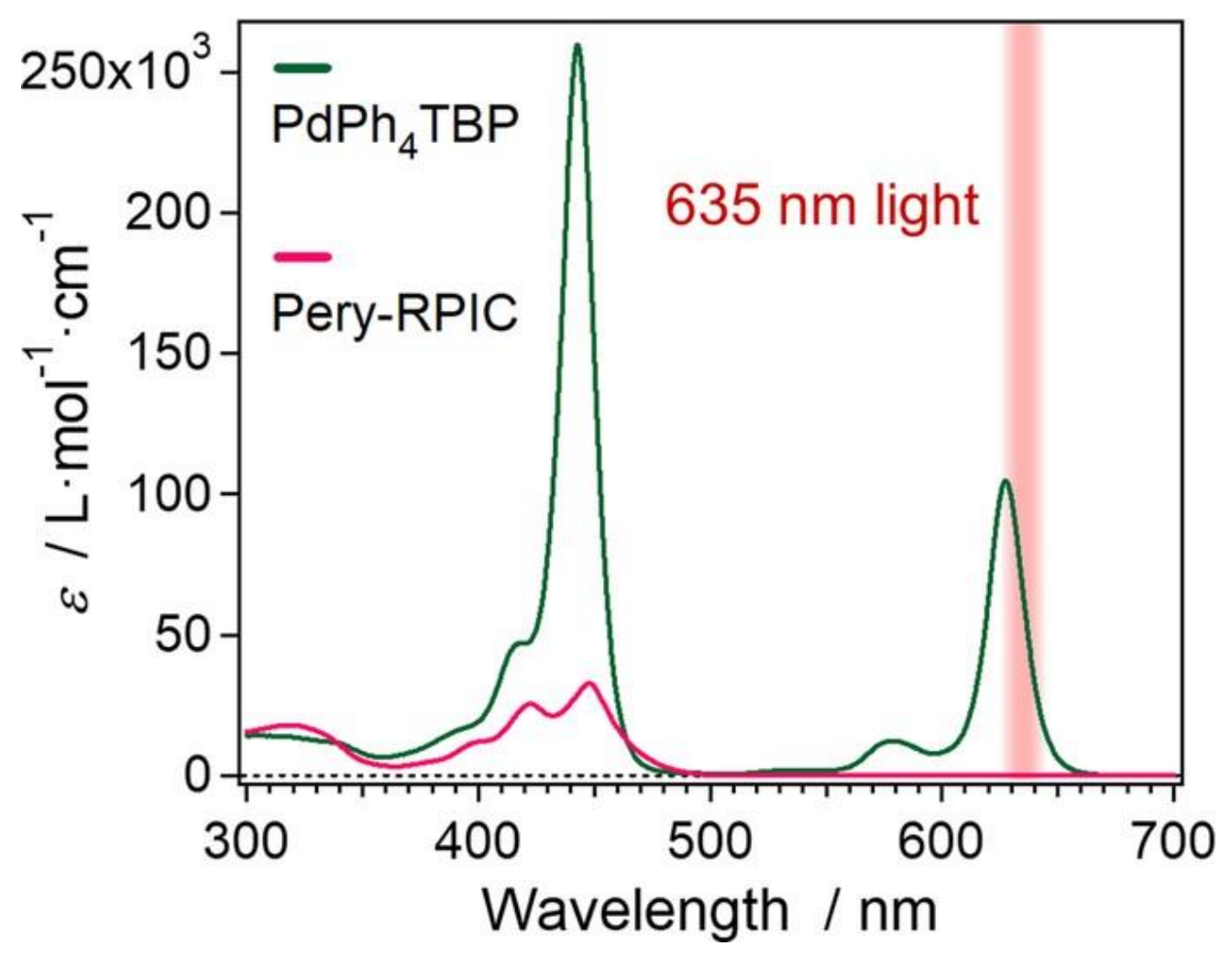

Figure 8

$58 \times 45 \mathrm{~mm}(300 \times 300$ DPI $)$ 
53

54

55

56

57

58

59

60

ACS Paragon Plus Environment 
(a)

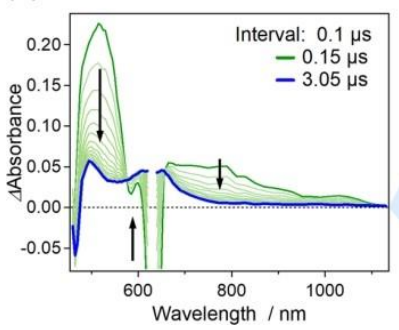

(b) Zoom Up

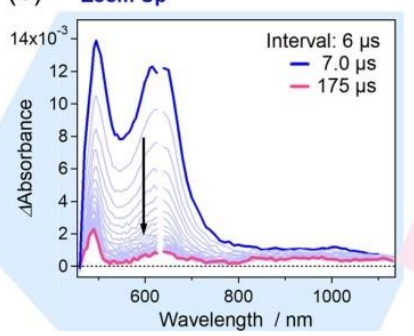

(c) Zoom Up

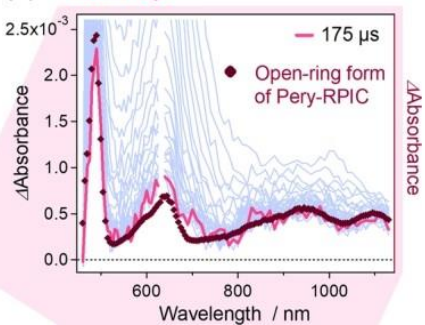

4

Figure 9 
(a)

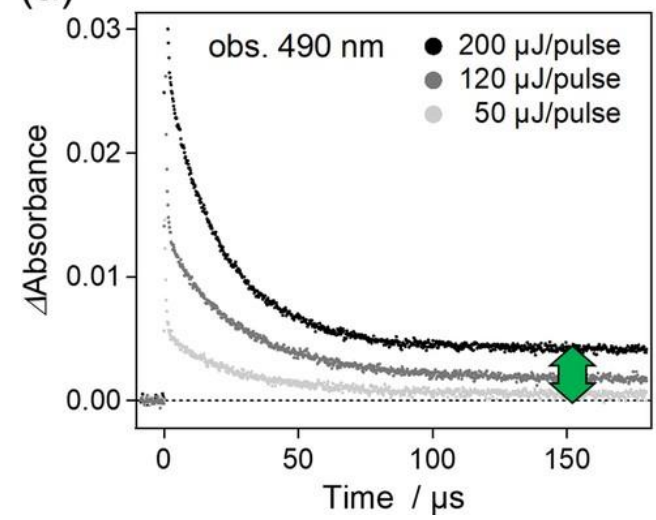

(b)

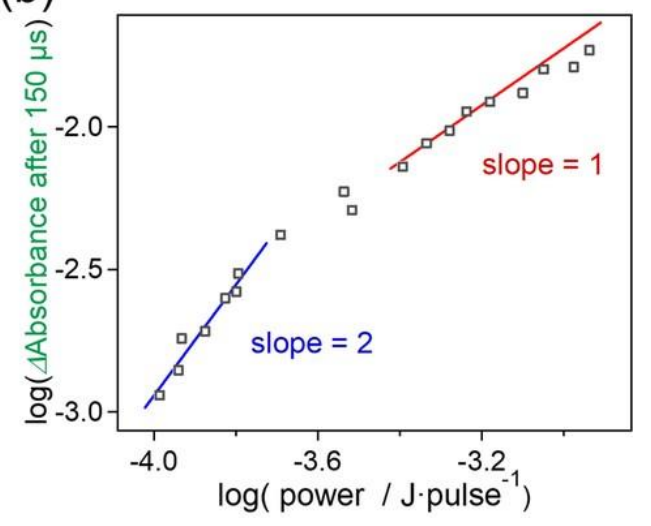

Figure 10

$84 \times 35 \mathrm{~mm}(300 \times 300$ DPI $)$ 
53

54

55

56

57

58

59

60

ACS Paragon Plus Environment 


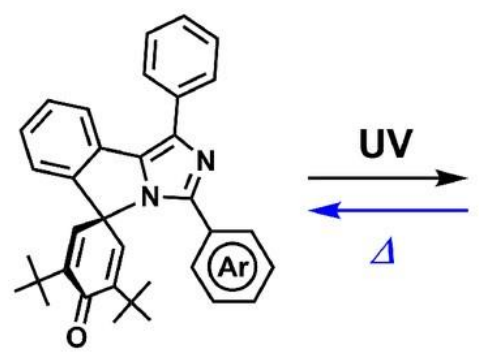

Closed

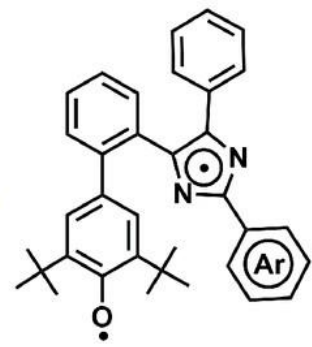

Biradical

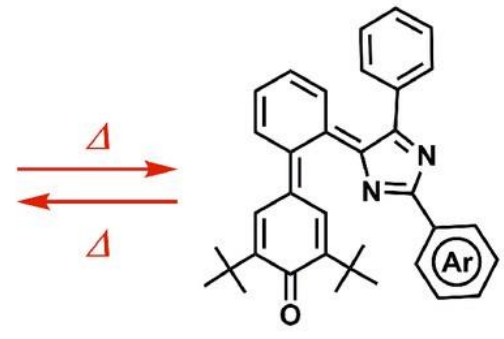

Quinoidal
3
RPIC: $A r=$ Phenyl

Pery-RPIC: Ar = Perylenyl
Scheme 1

$84 \times 39 \mathrm{~mm}(300 \times 300$ DPI $)$ 


\section{Page 23 of 24 Journal of the American Chemical Society}

1
2
3
4
5
6
7
8
9
10
1
1
1
1
1
1
1
17
18
15
20
21
2
23
2
25
26
2
28
25
30
31
32
33
3
35
36
3
38
35
40
4
4
4
4
4

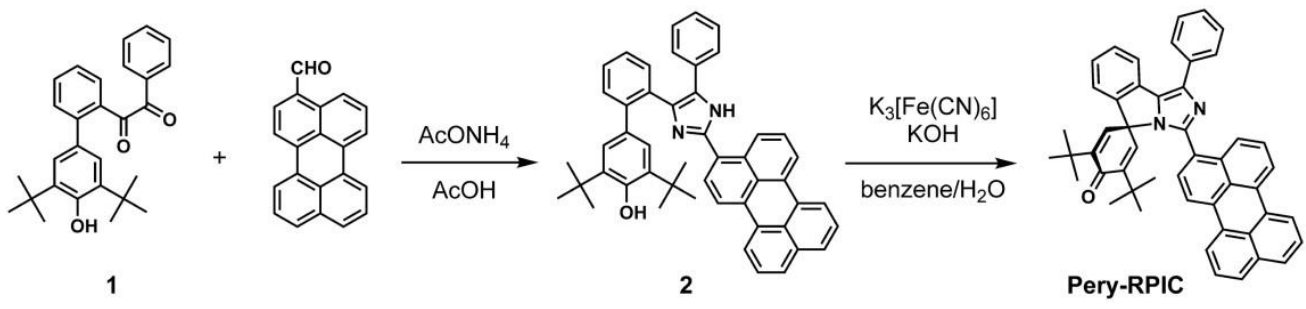

Scheme 2

$127 \times 29 \mathrm{~mm}(600 \times 600 \mathrm{DPI})$ 
53

54

55

56

57

58

59

60

ACS Paragon Plus Environment 


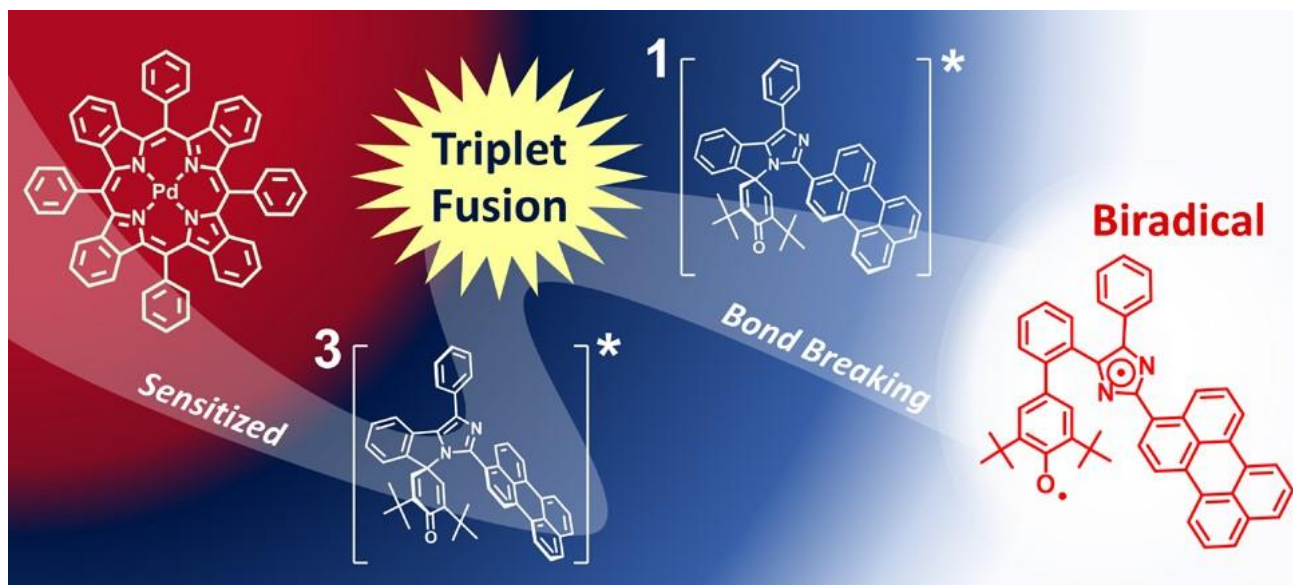

$82 \times 36 \mathrm{~mm}(300 \times 300$ DPI $)$ 